\title{
Increased consumption of fruit and vegetables for the primary prevention of cardiovascular diseases (Review)
}

Hartley L, Igbinedion E, Holmes J, Flowers N, Thorogood M, Clarke A, Stranges S, Hooper L, Rees $\mathrm{K}$

Hartley L, Igbinedion E, Holmes J, Flowers N, Thorogood M, Clarke A, Stranges S, Hooper L, Rees K. Increased consumption of fruit and vegetables for the primary prevention of cardiovascular diseases. Cochrane Database of Systematic Reviews 2013, Issue 6. Art. No.: CD009874.

DOI: 10.1002/14651858.CD009874.pub2.

www.cochranelibrary.com 
TABLE OF CONTENTS

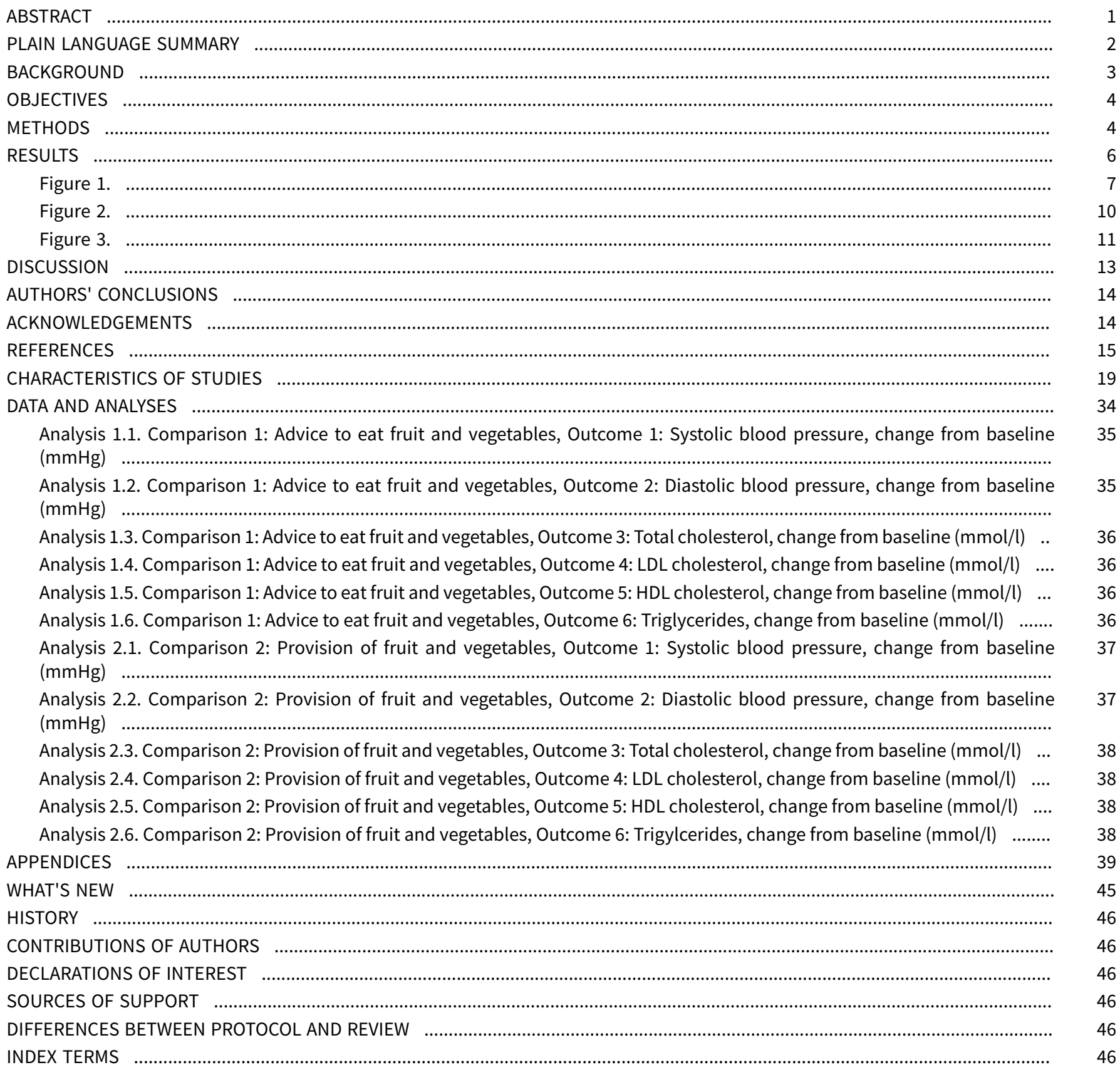


[Intervention Review]

\section{Increased consumption of fruit and vegetables for the primary prevention of cardiovascular diseases}

Louise Hartley ${ }^{1}$, Ewemade Igbinedion ${ }^{2}$, Jennifer Holmes ${ }^{3}$, Nadine Flowers ${ }^{2}$, Margaret Thorogood ${ }^{4}$, Aileen Clarke ${ }^{2}$, Saverio Stranges ${ }^{5}$, Lee Hooper 6 , Karen Rees ${ }^{7}$

1RTI Health Solutions, Manchester, UK. 2Division of Health Sciences, Warwick Medical School, University of Warwick, Coventry, UK. ${ }^{3}$ Warwick Medical School, University of Warwick, Coventry, UK. ${ }^{4}$ Public Health and Epidemiology, Division of Health Sciences, Coventry, UK. ${ }^{5}$ Department of Epidemiology and Biostatistics, Schulich School of Medicine and Dentistry, Western University, London, Canada. ${ }^{6}$ Norwich Medical School, University of East Anglia, Norwich, UK. ${ }^{7}$ Division of Health Sciences, Warwick Medical School, University of Warwick, Coventry, UK

Contact: Karen Rees, karen.rees@warwick.ac.uk, rees_karen@yahoo.co.uk.

Editorial group: Cochrane Heart Group.

Publication status and date: Edited (no change to conclusions), published in Issue 6, 2021.

Citation: Hartley L, Igbinedion E, Holmes J, Flowers N, Thorogood M, Clarke A, Stranges S, Hooper L, Rees K. Increased consumption of fruit and vegetables for the primary prevention of cardiovascular diseases. Cochrane Database of Systematic Reviews 2013, Issue 6. Art. No.: CD009874. DOI: 10.1002/14651858.CD009874.pub2.

Copyright @ 2013 The Cochrane Collaboration. Published by John Wiley \& Sons, Ltd.

Editorial note: This Cochrane Review has been superseded by a review entitled Vegan dietary pattern for the primary and secondary prevention of cardiovascular diseases (https://www.cochranelibrary.com/cdsr/doi/10.1002/14651858.CD013501.pub2/full).

\section{A B S T R A C T}

\section{Background}

There is increasing evidence that high consumption of fruit and vegetables is beneficial for cardiovascular disease (CVD) prevention.

\section{Objectives}

The primary objective is to determine the effectiveness of i) advice to increase fruit and vegetable consumption ii) the provision of fruit and vegetables to increase consumption, for the primary prevention of CVD.

\section{Search methods}

We searched the following electronic databases: The Cochrane Library (2012, issue 9-CENTRAL, HTA, DARE, NEED), MEDLINE (1946 to week 3 September 2012); EMBASE (1980 to 2012 week 39) and the Conference Proceedings Citation Index - Science on ISI Web of Science (5 October 2012). We searched trial registers, screened reference lists and contacted authors for additional information where necessary. No language restrictions were applied.

\section{Selection criteria}

Randomised controlled trials with at least three months follow-up (follow-up was considered to be the time elapsed since the start of the intervention) involving healthy adults or those at high risk of CVD. Trials investigated either advice to increase fruit and vegetable intake (via any source or modality) or the provision of fruit and vegetables to increase intake. The comparison group was no intervention or minimal intervention. Outcomes of interest were CVD clinical events (mortality (CVD and all-cause), myocardial infarction (MI), coronary artery bypass grafting (CABG) or percutaneous transluminal coronary angioplasty (PTCA), angiographically-defined angina pectoris, stroke, carotid endarterectomy, peripheral arterial disease (PAD)) and major CVD risk factors (blood pressure, blood lipids, type 2 diabetes). Trials involving multifactorial lifestyle interventions (including different dietary patterns, exercise) or where the focus was weight loss were excluded to avoid confounding. 


\section{Data collection and analysis}

Two review authors independently selected trials for inclusion, extracted data and assessed the risk of bias. Trials of provision of fruit and vegetables were analysed separately from trials of dietary advice.

\section{Main results}

We identified 10 trials with a total of 1730 participants randomised, and one ongoing trial. Six trials investigated the provision of fruit and vegetables, and four trials examined advice to increase fruit and vegetable consumption.The ongoing trial is examining the provision of an avocado-rich diet.The number and type of intervention components for provision, and the dietary advice provided differed between trials.

None of the trials reported clinical events as they were all relatively short term. There was no strong evidence for effects of individual trials of provision of fruit and vegetables on cardiovascular risk factors, but trials were heterogeneous and short term. Furthermore, five of the six trials only provided one fruit or vegetable. Dietary advice showed some favourable effects on blood pressure (systolic blood pressure (SBP): mean difference (MD) -3.0 mmHg (95\% confidence interval ( $\mathrm{Cl}$ ) -4.92 to -1.09), diastolic blood pressure (DBP): $\mathrm{MD}-0.90 \mathrm{mmHg}(95 \%$ $\mathrm{Cl}-2.03$ to 0.24$)$ ) and low-density lipoprotein (LDL) cholesterol but analyses were based on only two trials. Three of the 10 included trials examined adverse effects, which included increased bowel movements, bad breath and body odour.

\section{Authors' conclusions}

There are very few studies to date examining provision of, or advice to increase the consumption of, fruit and vegetables in the absence of additional dietary interventions or other lifestyle interventions for the primary prevention of CVD. The limited evidence suggests advice to increase fruit and vegetables as a single intervention has favourable effects on CVD risk factors but more trials are needed to confirm this.

\section{PLAIN LANGUAGE SUMMARY}

\section{Increased fruit and vegetable intake to prevent cardiovascular disease}

Cardiovascular disease (CVD) is a global burden and varies between regions. This regional variation has been linked in part to dietary factors and low fruit and vegetable intake has been associated with higher rates of CVD. This review assessed the effectiveness of increasing fruit and vegetable consumption as a single intervention without the influence of other dietary patterns or other lifestyle modifications in healthy adults and those at high risk of CVD for the prevention of CVD. We found 10 trials involving 1730 participants in which six examined the provision of fruit and vegetables to increase intake and four trials examined dietary advice to increase fruit and vegetable intake. There were variations in the type of fruit and vegetable provided but all interventions investigating provision involved only one fruit or vegetable component. There were also variations in the number of fruit and vegetables that participants were advised to eat. Some studies advised participants to eat at least five servings of fruit and vegetables a day while others advised at least eight or nine servings per day.The duration of the interventions ranged from three months to one year. Adverse effects were reported in three of the included trials and included increased bowel movements, bad breath and body odour. None of the included trials were long enough to examine the effect of increased fruit and vegetable consumption on cardiovascular disease events such as heart attacks. There was no strong evidence that provision of one type of fruit or vegetable had beneficial effects on blood pressure and lipid levels but most trials were short term. There was some evidence to suggest beneficial effects of dietary advice to increase fruit and vegetable consumption but this is based on findings from two trials. More trials are needed to confirm these findings. 


\section{B A C K G R O U N D}

\section{Description of the condition}

Cardiovascular disease (CVD) is one of the leading causes of death worldwide (WHO 2011). In 2008 it accounted for $30 \%$ of total global deaths, with 6.2 million deaths the consequence of stroke and 7.2 million due to coronary heart disease (CHD) (WHO 2011). The burden of CVD also varies substantially between regions (MüllerNordhorn 2008), for example, death from Ischaemic heart disease in France is a quarter of that of the United Kingdom (UK) (Law 1999).

Dietary factors may play a vital role in the development of CVD and its risk factors and may contribute to the geographic variability in CVD morbidity and mortality (Scarborough 2011; Yusuf 2001). Such factors are important, not only because they have been linked to CVD development, but also because they can be modified. This makes them one of the main targets for interventions aimed at primary prevention and management of CVD.

One dietary factor that should be considered in the primary prevention of CVD is fruit and vegetable intake. Indeed, a low consumption of fruit and vegetables (less than 400 grammes [g] per day) is thought to be one of the top 10 risk factors for global mortality and is estimated to result in 1.7 million global deaths a year (WHO 2004). Of these global deaths, $14 \%$ are from gastrointestinal cancer, $11 \%$ are due to ischaemic heart disease and $9 \%$ are from stroke. In the European Union, New Zealand and Australia $3.5 \%, 2.1 \%$ and $2.8 \%$ respectively of disease burden is considered to be a consequence of low fruit and vegetable intake (Begg 2007; Pomerleau 2004; Tobias 2001), with, in particular, 9.6\% of the CVD disease burden in Australia due to a low intake of fruit and vegetables (Begg 2007).

Conversely, it has been shown that a high consumption of fruit and vegetables can have a protective role for some chronic diseases including CVD (Hooper 2007). A number of cohort studies have shown that the risk of $\mathrm{CHD}$ is associated with lower consumption of fruit and vegetables (Bazzano 2002; Liu 2000; Liu 2001). Joshipura and colleagues, for example, showed in a large observational study $(84,251$ women and 42,148 men) that a high intake of fruit of vegetables was associated with reduced risk of developing CHD. This was particularly the case for those fruit and vegetables rich in vitamin C and leafy green vegetables (Joshipura 2001). It has been estimated that an increase in fruit and vegetable intake could reduce the burden of ischaemic stroke and ischaemic heart disease by as much as $19 \%$ and $31 \%$ respectively (Lock 2005). Furthermore, it is estimated that approximately 2.7 million lives a year could be saved by increasing fruit and vegetable consumption to $400 \mathrm{~g}$ per day or over (WHO 2004).

Observational studies have shown that high levels of fruit and vegetable intake are associated with increased psychological well being (Blanchflower 2012), a reduction in the risk of CVD (Joshipura 2001; Liu 2000; Liu 2001) and a reduction in type 2 diabetes (Carter 2010). As a result, many national and international guidelines recommend at least five portions of fruit and/or vegetables a day (a portion equates to 80 g) (Agudo 2004; NHS 2009; U.S. Department of Agriculture 2005). However, such guidelines are not always followed. This appears to be the case in the UK where it is estimated that only $27.7 \%$ of the general population reach this target (Maheswaran 2013).

\section{Description of the intervention}

There are many complex determinants involved in fruit and vegetable intake. As a consequence of this, a variety of conceptual frameworks are used to help develop interventions aimed at increasing fruit and vegetable consumption (Wolfenden 2012). For instance, a conceptual framework may suggest that interventions aimed at personal and cultural factors are more effective in increasing fruit and vegetable consumption than an intervention targeting only personal factors. It is suggested that for addressing changes to dietary intake, such as fruit and vegetable consumption, a social ecological framework that uses behaviour change theories at different levels of influence is best (Peterson 2002).

The interventions investigated in this review will include those that provide advice to increase fruit and vegetable consumption or those that provide fruit and vegetables themselves to increase consumption. Advice can take many forms in that it may be written or verbal, involve a single or multiple contact and may be delivered by commercial organisations, health professionals or government organisations. Provision may include only one, or more fruit(s) and/ or vegetable(s) and be provided in the workplace, at community centres or in the home to name but a few.

\section{How the intervention might work}

Evidence from observational and experimental studies suggests that a high consumption of fruit and vegetables, that is more than $400 \mathrm{~g}$ or more than five portions a day, may be beneficial for the prevention and treatment of CVD (Ness 1997). However, the exact mechanisms by which increased fruit and vegetable consumption reduce CVD risk are not known. It may be due to fruit and vegetables containing protective elements including vitamins, minerals, antioxidants, micronutrients and phytochemicals (Department of Health 2010; Miller 2000; Van Duyn 2000). There are many potential mechanisms through which these protective elements can act to reduce blood pressure, reduce antioxidant stress, lower the serum level of low-density lipoprotein cholesterol and improve the regulation of haemostasis (Asgard 2007; Dauchet 2006; Suido 2002).

Theories have been developed to explain the mechanisms by which lifestyle changes such as fruit and vegetable provision and advice interventions influence fruit and vegetable intake. These tend to be based on the Health Belief Model (Rosenstock 1966), The Theory of Planned Behaviour (Ajzen 1991), Social cognitive theory (Bandura 1986) or the Stages of Change Model (Prochaska 1984). All four theories emphasise the dynamic nature of beliefs and suggest that in order for behaviours to change, changes need to be made to a person's perceived norms, attitudes, knowledge, skills, and expectancies (Ogden 2001; Wolfenden 2012). Social-ecological theories have also been used to explain the mechanisms by which interventions aimed at increasing fruit and vegetable intake may work. These theories suggest that a person's health behaviour is influenced by a multitude of factors including not only intraand interpersonal factors but also organisational and community factors and those relating to public policy (Robinson 2008).

\section{Why it is important to do this review}

Many factors determine the intake of fruit and vegetables in adults (Pollard 2002). These include not only demographic and lifestyle factors but also sensory appeal and availability (Anderson 1994; Brug 1995; Clark 1998; Lennernas 1997; Thompson 1999). Although observational studies investigating the factors that determine 
fruit and vegetable intake provide considerable information to aid in the development of interventions, they do not examine the effectiveness of interventions to increase fruit and vegetable consumption. Some systematic reviews have attempted to do this (Ammerman 2002; Brunner 2007; Contento 1995; Miller 2000a; Pomerleau 2005). Pomerleau et al. (Pomerleau 2005), for example, conducted a systematic review that investigated the effectiveness of interventions designed to promote the intake of fruit and vegetables. They found that the largest increase in fruit and vegetable consumption was for interventions that targeted highrisk populations or those with a pre-existing disease, while a small increase of between 0.1 and 1.4 servings of fruit and vegetables a day was found for interventions promoting fruit and vegetable intake in healthy adults. This was similar to the findings of Brunner et al. (Brunner 2007) who found that dietary advice, when compared to no advice, increased the consumption of fruit and vegetables by 1.25 servings per day in healthy adults.

However, these systematic reviews do not always focus solely on the intake of fruit and vegetables (Brunner 2007; Contento 1995). The systematic review by Pomerleau (2005) does not solely focus on CVD (Pomerleau 2005), and other reviews include children (Burchett 2003; Miller 2000a).

We are focusing our attention on adults since a Cochrane review is already being undertaken in assessing the evidence for interventions for increasing fruit and vegetable consumption in children aged up to five years (Wolfenden 2012), and another on community-based interventions to increase fruit and vegetable consumption for five to 18 year olds (Ganann 2010). A comprehensive systematic review is needed that thoroughly examines interventions providing advice to increase fruit and vegetable consumption and the provision of fruit and vegetables to increase consumption, in healthy adults or those with cardiovascular risk factors to determine their effectiveness in CVD prevention. This will provide guidance not only for national and international governments but also for local authorities, practitioners and members of the public.

\section{OB JECTIVES}

The primary objective is to determine the effectiveness of i) advice to increase fruit and vegetable consumption ii) the provision of fruit and vegetables to increase consumption, on mortality (cardiovascular and all-cause), non-fatal CVD endpoints (myocardial infarction (MI), coronary artery bypass grafting (CABG), percutaneous transluminal coronary angioplasty (PTCA), angina, or angiographically-defined coronary heart disease (CHD), stroke, carotid endarterectomy, peripheral arterial disease (PAD)), changes in blood pressure (systolic and diastolic blood pressure) and blood lipids (total cholesterol, high-density lipoprotein (HDL) cholesterol, low-density lipoprotein (LDL) cholesterol, triglycerides), the occurrence of type 2 diabetes, health-related quality of life, adverse effects and costs.

\section{METHODS}

\section{Criteria for considering studies for this review}

\section{Types of studies}

Randomised controlled trials (RCTs) including cluster-randomised trials and cross-over trials.

\section{Types of participants}

Adults (people from the age of 18 onwards) of all ages from the general population and those who are at high risk of CVD due to the presence of major CVD risk factors such as smoking, dyslipidaemia or hypertension. The review focused on the effects of fruit and vegetable consumption for the primary prevention of CVD. We therefore excluded studies where more than $25 \%$ of participants had CVD at baseline including those who have experienced a previous $\mathrm{MI}$, stroke, revascularisation procedure (CABG or PTCA), those with angina, or angiographically-defined CHD, cerebrovascular disease (stroke) and PAD. We also excluded studies where more than $25 \%$ of the participants had type 2 diabetes as while patients with type 2 diabetes are at increased risk of CVD, interventions for diabetes are covered specifically by the Cochrane Metabolic and Endocrine Disorders review group.

\section{Types of interventions}

The interventions included i) specific dietary advice to increase fruit and vegetable consumption or ii) the provision of fruit and vegetables (participants are provided with fruits and vegetables as part of the intervention) as a means to increase consumption. All interventions were to include whole fruit and vegetables only, interventions involving fruit and vegetable extracts were excluded. Both provision and advice interventions could be delivered in any setting, by any individual or modality.

Studies examining advice to increase fruit and vegetable intake were examined separately from those investigating the provision of fruit and vegetables. Multi-factorial lifestyle interventions (including additional dietary interventions e.g. reduced fat and other lifestyle interventions e.g. exercise) and trials focusing on weight loss were not included in this review to avoid confounding.

We focused on follow-up periods of three months or more. Followup was considered to be the time elapsed since the start of the intervention and therefore any trials with an intervention duration of less than 12 weeks were excluded. Trials were only considered where the comparison group was no intervention (usual diet) or minimal intervention (e.g. leaflets (dietary or otherwise) with no person-to-person interaction or reinforcement).

\section{Types of outcome measures}

Endpoints were measured using validated measures.

\section{Primary outcomes}

1. Cardiovascular mortality.

2. All-cause mortality.

3. Non-fatal endpoints such as MI, CABG, PTCA, angina, or angiographically-defined $\mathrm{CHD}$, stroke, carotid endarterectomy, PAD.

\section{Secondary outcomes}

1. Changes in blood pressure (systolic and diastolic blood pressure) and blood lipids (total cholesterol, HDL cholesterol, LDL cholesterol, triglycerides).

2. Occurrence of type 2 diabetes as a major CVD risk factor.

3. Health-related quality of life.

4. Adverse effects (as defined by the authors of the included trials). 5. Costs. 


\section{Search methods for identification of studies}

\section{Electronic searches}

The following electronic databases were searched: The Cochrane Library (2012, issue 9), (including the Cochrane Central Register of controlled Trials (CENTRAL) and NHS Centre for Reviews and Dissemination (CRD) databases Health Technology Assessment (HTA), Database of Abstracts of Reviews of Effectiveness (DARE) and NHS Economic Evaluation Database (NEED)); MEDLINE (1946 to week 3 September 2012); EMBASE (1980 to 2012 week 39) and the Conference Proceedings Citation Index - Science on ISI Web of Science (5 October 2012). We searched trial registers, screened reference lists and contacted authors for additional information where necessary. No language restrictions were applied.

Medical Subject Headings (MeSH) or equivalent and text word terms were use with searches designed in accordance with Cochrane Heart Group methods and guidance. There were no language restrictions.

Searches were tailored to individual databases. The search strategies for each database are shown in Appendix 1.

\section{Searching other resources}

Reference lists of reviews and retrieved articles were checked for additional studies.

We searched the metaRegister of controlled trials (mRCT) (www.controlled-trials.com/mrct), Clinicaltrials.gov (www.clinicaltrials.gov) and the WHO International Clinical Trials Registry Platform (ICTRP) (http://apps.who.int/trialsearch/) for ongoing trials and unpublished or part-published trials.

Citation searches were performed on key articles. Google Scholar was also used to search for further studies.

We contacted experts in the field for unpublished and ongoing trials and authors were contacted where necessary for additional information.

\section{Data collection and analysis}

\section{Selection of studies}

Review authors (LH, El, NF) independently reviewed the titles and abstracts identified from the searching. Following this initial screening, the full text reports of the potentially relevant studies were obtained and the same two review authors (LH, EI) independently selected relevant studies using predetermined inclusion criteria. In all cases, disagreements concerning study inclusion were resolved by consensus, a third review author (Karen Rees (KR)) was consulted if disagreement persisted.

\section{Data extraction and management}

Data extraction was carried out independently by two review authors (LH, Jennifer Holmes (JH)) using a proforma and chief investigators were contacted to provide additional relevant information if necessary.

The following details were extracted from each study.
3. Participant characteristics.

4. Intervention (advice or provision of fruit and vegetables, personnel, intensity, duration, follow-up).

5. Comparison group (no intervention or details of minimal intervention).

6. Outcome data (outcome assessment, adverse effects).

7. Methodological quality (randomisation, blinding, attrition).

Disagreements about extracted data were resolved by consensus and a third reviewer (KR) was consulted if disagreement persisted.

\section{Assessment of risk of bias in included studies}

Risk of bias was assessed independently by two review authors $(\mathrm{LH}, \mathrm{JH})$ by examining the quality of the random sequence generation and allocation concealment, description of drop-outs and withdrawals (including intention-to-treat analysis), blinding (participant, personnel and outcome assessment) and selective outcome reporting (Higgins 2011).

\section{Measures of treatment effect}

Data was processed in accordance with the Cochrane Handbook for Systematic Reviews of Interventions (Higgins 2011). For continuous outcomes net changes were compared (i.e. intervention group minus control group differences) and a mean difference (MD) and 95\% confidence intervals (Cl's) calculated for each study.

\section{Assessment of heterogeneity}

For each outcome, tests of heterogeneity were conducted (using $\mathrm{Chi}^{2}$ test of heterogeneity and $\mathrm{I}^{2}$ statistic). If no heterogeneity was present a fixed-effect meta-analysis was performed. If there was substantial heterogeneity ( 12 greater than $50 \%)$ the review authors looked for possible explanations for this (e.g. intervention and participants). If the heterogeneity could not be explained, we considered the following options:

1. provide a narrative overview and not aggregate the studies at all;

2. use a random-effects model with appropriate cautious interpretation.

\section{Subgroup analysis and investigation of heterogeneity}

Results were stratified by i) advice to increase fruit and vegetable consumption and ii) the provision of fruit and vegetables to increase consumption. Trials could not be stratified by baseline risk and the effects of intensity and duration of the intervention due to the small number of trials included in the review.

\section{Sensitivity analysis}

We performed sensitivity analysis excluding studies at high risk of bias (e.g. those with loss to follow-up more than $20 \%$ without intention-to-treat analysis). We intended to examine the effects of "time and attention" given to participants in the intervention and control groups as potential confounders, and the effects of publication bias using funnel plots and tests of asymmetry (Egger 1997), but these could not be carried out due to the small number of trials included in the review.

1. Study design.

2. Study setting. 


\section{RES U L T S}

\section{Description of studies}

\section{Results of the search}

The electronic searches generated 7283 hits after duplicates were removed. Screening of titles and abstracts identified 298 papers to go forward for formal inclusion and exclusion. Of these, 10 RCTs met the inclusion criteria. We also identified one ongoing trial from trial registers. Details of the flow of studies through the review are shown in the PRISMA flow diagram in Figure 1. 
Figure 1. Study flow diagram.

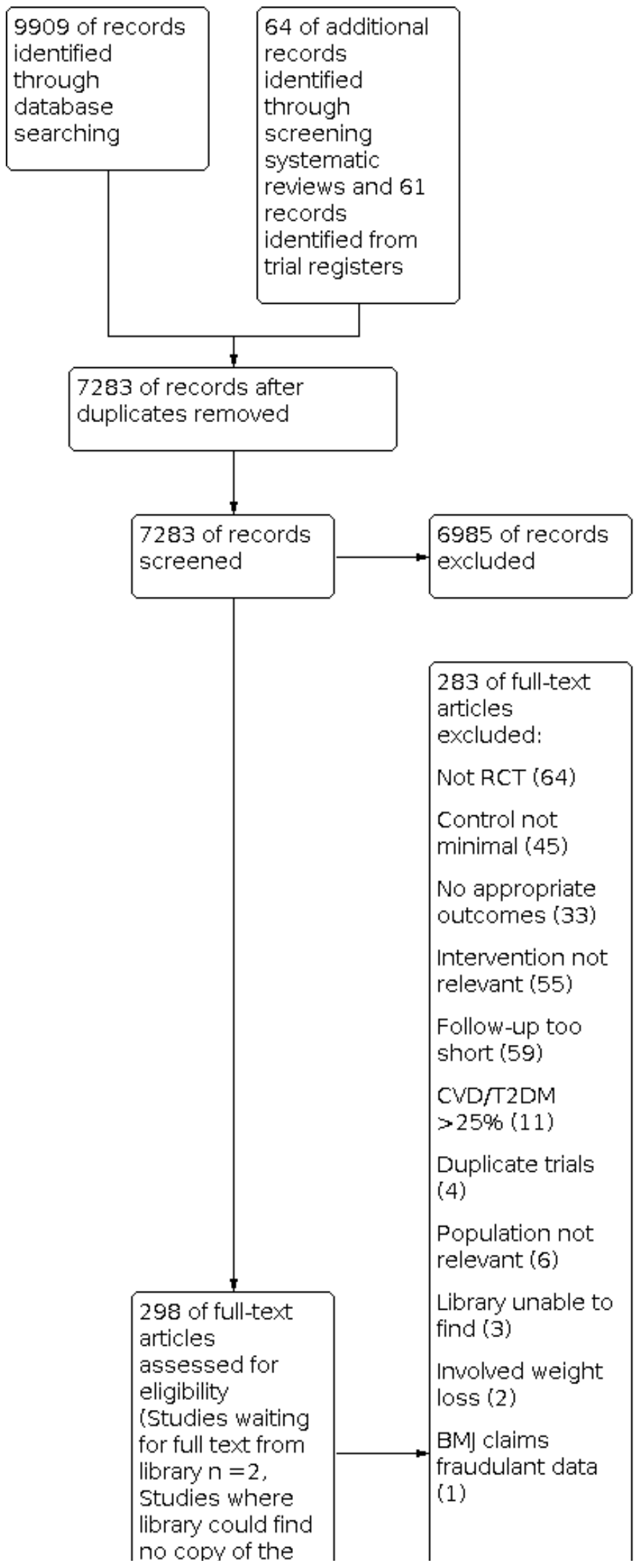


Figure 1. (Continued)

\begin{tabular}{l}
$\begin{array}{l}\text { library could find } \\
\text { no copy of the } \\
\text { study } n=2)\end{array}$ \\
\hline $\begin{array}{l}10 \text { studies } \\
\text { included in } \\
\text { qualitative } \\
\text { synthesis. Also } \\
\text { 1 ongoing trial } \\
\text { was identified } \\
\text { and there are } 4 \\
\text { studies awaiting } \\
\text { classification. }\end{array}$ \\
\hline $\begin{array}{l}\text { 7 studies } \\
\text { included in the } \\
\text { quantitative } \\
\text { synthesis } \\
\text { (meta-analysis) } \\
\text { of secondary } \\
\text { outcomes } \\
\text { (cardiovascular } \\
\text { risk factors) }\end{array}$ \\
\hline
\end{tabular}

\section{Included studies}

Details of the studies included in the review are shown in the Characteristics of included studies table. Ten trials with 1730 participants met the inclusion criteria. Four of the 10 trials recruited only female participants (Dichi 2011; Djuric 2006; Gravel 2009; Maskarinec 1999). Six trials were conducted in the U.S.A (Djuric 2006; Finley 2007; Fujioka 2006; Gardner 2007; Maskarinec 1999; Smith-Warner 2000), one trial in Canada (Gravel 2009), one in Brazil (Dichi 2011), and two in the UK (John 2002; Thies 2012).

None of the included studies had interventions that provided fruit and vegetables and gave advice. Six of the 10 trials examined the effects of providing fruit and vegetables to increase consumption (Dichi 2011; Finley 2007; Fujioka 2006; Gardner 2007; Gravel 2009; Thies 2012) and four examined the effects of dietary advice to increase fruit and vegetable intake (Djuric 2006; John 2002; Maskarinec 1999; Smith-Warner 2000). For those studies examining the effects of provision of fruit and vegetables there was variability in the types of fruit and vegetables provided and the portion size. Furthermore, five of the six provision trials only provided one fruit or vegetable. One study looked at the provision of 25 $\mathrm{g} /$ day of soy (Dichi 2011), one looked at the provision of $130 \mathrm{~g}$ of cooked pinto beans daily (Finley 2007), another examined the effects of half a grapefruit three times a day (Fujioka 2006), one study examined the provision of raw garlic on a sandwich (Gardner 2007), one study looked at a high tomato diet (Thies 2012) and one trial looked at the provision of $750 \mathrm{~mL}$ of legumes a week (Gravel 2009). Similarly, the type of dietary advice to increase fruit and vegetable consumption also varied between studies. Portions of fruit and vegetables included five or more portions a day (John
2002), at least eight servings daily (Smith-Warner 2000), and at least nine servings a day (Djuric 2006; Maskarinec 1999). In addition, the modality of the advice provided differed between studies. In two studies, advice was provided by individualised in-person dietary counselling with monthly group meetings (Djuric 2006; Maskarinec 1999). In another study participants were provided with a portion guide, leaflets on barriers to increasing fruit and vegetable consumption and an action plan to increase fruit and vegetable consumption by a research nurse who also introduced the benefits of increasing fruit and vegetable intake (John 2002). In the remaining study a nutritionist helped participants to formulate a plan to help them increase their fruit and vegetable intake and provided participants with educational materials on this topic. Participants were also taught behavioural modification strategies to identify personal barriers to adherence (Smith-Warner 2000). The dietary advice interventions took place in health centres (John 2002) and a digestive healthcare unit (Smith-Warner 2000). The two remaining studies did not state where there interventions took place (Djuric 2006; Maskarinec 1999).

The duration of the intervention and follow-up periods varied between the included studies. Four of the studies had three to six months follow-up (Dichi 2011; Finley 2007; Fujioka 2006; Thies 2012), four a follow-up of six months (Gardner 2007; Gravel 2009; John 2002; Maskarinec 1999), and two studies a follow-up of one year (Djuric 2006; Smith-Warner 2000).

Studies were also variable in the types of participants they recruited. Two studies were conducted in women with metabolic syndrome (Dichi 2011; Gravel 2009), one study was conducted in healthy post-menopausal women with a family history of breast 
cancer (Djuric 2006), one was conducted in participants with LDL concentrations of $130-190 \mathrm{mg} / \mathrm{dL}$ and triglyceride levels of less than $250 \mathrm{mg} / \mathrm{dL}$ (Gardner 2007), one study included participants who were obese (Fujioka 2006), another study was conducted in patients who had colorectal adenomatous polyps in the five years before the study (Smith-Warner 2000), one study included patients who were pre-metabolic or healthy (Finley 2007) and three studies were conducted in healthy participants (John 2002; Maskarinec 1999; Thies 2012).

Four studies examining the provision of fruit and vegetables to increase consumption are awaiting classification. Details of these studies are provided in the Characteristics of studies awaiting classification table. The first trial examined fruit and vegetable puree and juice drinks in healthy participants (George 2009). The second trial examined three different diets on serum cholesterol in healthy volunteers (Groen 1952). The third study awaiting classification looked at $45 \mathrm{~g} /$ day of blueberries or blackberries in postmenopausal women who smoked (Teeple (2011)), while the forth study examined seven or more portions of fruit and vegetables daily for 12 weeks in overweight participants (Wallace 2012).
One ongoing trial examining the provision of fruit and vegetables to increase consumption was identified (Wang 2011). Details of this study are shown in the Characteristics of ongoing studies table. The study examined an avocado-rich diet (Wang 2011). The anticipated end date for this study was May 2012 but as of yet, no results have been published.

\section{Excluded studies}

Details and reasons for exclusion for the studies that most closely missed the inclusion criteria are provided in the Characteristics of excluded studies table. Reasons for exclusion for the majority of studies were alternative designs (not RCTs), the intervention was not relevant, studies were short term with less than three months follow-up and the control group did not receive a minimal intervention or no intervention (see Figure 1).

\section{Risk of bias in included studies}

Details are presented for each of the included trials in the 'Risk of bias' tables in the Characteristics of included studies and summaries are presented in Figure 2 and Figure 3. 
Figure 2. 'Risk of bias' summary: review authors' judgements about each risk of bias item for each included study.

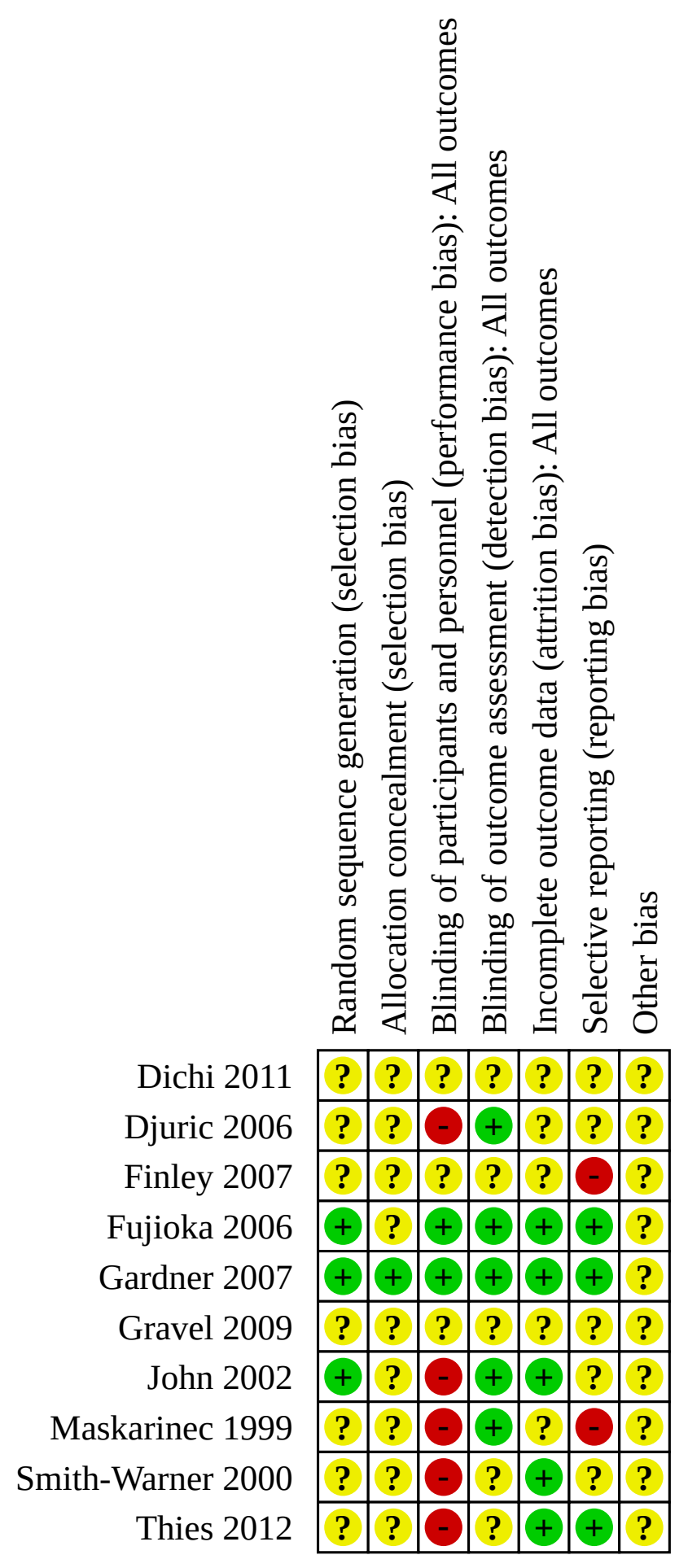


Figure 3. 'Risk of bias' graph: review authors' judgements about each risk of bias item presented as percentages across all included studies.

Random sequence generation (selection bias)

Allocation concealment (selection bias)

Blinding of participants and personnel (performance bias): All outcomes

Blinding of outcome assessment (detection bias): All outcomes Incomplete outcome data (attrition bias): All outcomes

Selective reporting (reporting bias)

Other bias

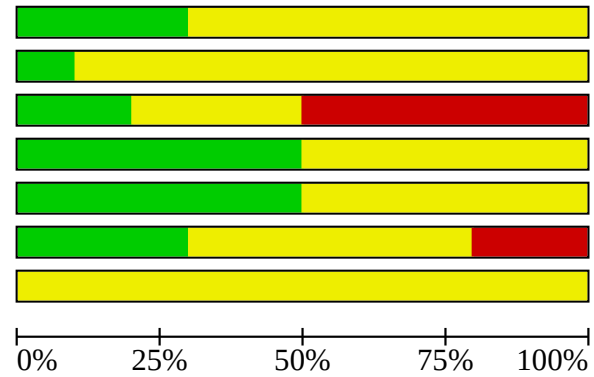

Low risk of bias

$\square$ Unclear risk of bias

High risk of bias

\begin{abstract}
Allocation
The methods of random sequence generation were unclear in seven of the 10 included studies (Dichi 2011; Djuric 2006; Finley 2007; Gravel 2009; Maskarinec 1999; Smith-Warner 2000; Thies 2012). In the three studies where the random sequence generation methods were stated, the methods were judged to be of low risk of bias (Fujioka 2006; Gardner 2007; John 2002). The methods of allocation concealment were unclear in nine of the 10 included studies (Dichi 2011; Djuric 2006; Finley 2007; Fujioka 2006; Gravel 2009; John 2002; Maskarinec 1999; Smith-Warner 2000; Thies 2012). In the one study which stated the method of allocation concealment, the method was judged of low risk of bias (Gardner 2007).
\end{abstract}

\section{Blinding}

Blinding participants and personnel was unclear in three of the 10 included studies. Four trials were of dietary advice where blinding of participants to the intervention was impossible (Djuric 2006; John 2002; Maskarinec 1999; Smith-Warner 2000) and these were regarded as at high risk of bias. Similarly, it may also difficult to blind participants in trials of the provision of fruit and vegetables. One study stated that it was single-blind and so was regarded as at high risk of bias (Thies 2012), while two studies stated that they were double-blind and were regarded as at low risk of bias (Fujioka 2006; Gardner 2007). The blinding of outcome assessors was unclear in five of the included studies (Dichi 2011; Finley 2007; Gravel 2009; Smith-Warner 2000; Thies 2012) but five studies stated that outcome assessors were blinded (Djuric 2006; Fujioka 2006; Gardner 2007; John 2002; Maskarinec 1999).

\section{Incomplete outcome data}

Five of the 10 included studies reported losses to follow-up, had a similar number of losses between the intervention and control arms, and/or stated the reasons for losses to follow-up (Fujioka 2006; Gardner 2007; John 2002; Smith-Warner 2000; Thies 2012).These studies were considered to be at low risk of bias. In another five trials, the reporting of incomplete outcome data was judged as unclear as they either did not report losses to follow-up (Dichi 2011; Gravel 2009) or did not report the reasons for losses to follow-up (Djuric 2006;Finley 2007; Maskarinec 1999).

\section{Selective reporting}

For five of the 10 included studies the risk of bias for selective reporting was unclear as there was insufficient information available for a judgement to be made (Dichi 2011; Djuric 2006; Gravel 2009; John 2002; Smith-Warner 2000). For two studies, the risk of bias was judged as high (Finley 2007; Maskarinec 1999) because lipid levels were reported in graphical form with no usable numbers for meta-analysis (Finley 2007) or because lipid levels were presented in the analysis but were not stated in the methods as an outcome (Maskarinec 1999). Three of the 10 included studies were judged to be of low risk of bias as the studies clearly stated primary and secondary outcomes and reported their results (Fujioka 2006; Gardner 2007; Thies 2012).

\section{Other potential sources of bias}

For all included studies there was insufficient information to judge the risk of bias from other potential sources.

\section{Effects of interventions}

\section{Advice to increase the consumption of fruit and vegetables}

Four trials examined dietary advice to increase fruit and vegetable consumption with follow-up periods of over six months (Djuric 2006; John 2002; Maskarinec 1999; Smith-Warner 2000). No trials were found with a follow-up of three to six months.

\section{Clinical Events}

None of the included studies provided clinical event data.

\section{Cardiovascular risk factors}

\section{Blood pressure}

Two of the four studies that examined dietary advice to increase the consumption of fruit and vegetables measured blood pressure (John 2002; Smith-Warner 2000). In one study, this was at six months (John 2002) and in the other study at 12 months (SmithWarner 2000). From the pooled analysis, advice to eat fruit and vegetables significantly reduced systolic blood pressure (mean difference (MD) $-3.0 \mathrm{mmHg}$ (95\% confidence interval (Cl) -4.92 to -1.09)) (Analysis 1.1) (891 participants) but the reduction in diastolic blood pressure was not statistically significant (MD -0.90 $\mathrm{mmHg}(95 \% \mathrm{Cl}-2.03$ to 0.24$)$ ) (Analysis 1.2) (891 participants). No heterogeneity was found between trials $(12=0 \%)$.

\section{Lipid levels}

Four studies measured total cholesterol (Djuric 2006; John 2002; Maskarinec 1999; Smith-Warner 2000). Two studies measured total 
cholesterol at six months (John 2002; Maskarinec 1999) and two studies measured this at 12 months (Djuric 2006; Smith-Warner 2000). The pooled analysis showed no effect of the intervention on total cholesterol levels (MD $-0.01 \mathrm{mmol} / \mathrm{L}(95 \% \mathrm{Cl}-0.11$ to 0.09)) (Analysis 1.3) (970 participants). No heterogeneity was found between trials $(12=0 \%)$.

Two trials examined the effects of dietary advice on LDL cholesterol (Djuric 2006; Smith-Warner 2000); both at 12 months. Both trials could be pooled statistically and showed a reduction in LDL cholesterol but this did not reach statistical significance (MD -0.17 $\mathrm{mmol} / \mathrm{L}(95 \% \mathrm{Cl}-0.38$ to 0.03$)$ ) (Analysis 1.4) (251 participants). No heterogeneity was found between trials $\left(I^{2}=0 \%\right)$.

Two studies also measured HDL cholesterol (Djuric 2006; SmithWarner 2000) at 12 months and the pooled data for these studies showed no effect of the intervention on HDL cholesterol levels (MD $-0.01(95 \% \mathrm{Cl}-0.10$ to 0.08$)$ ) (Analysis 1.5$)$ (251 participants). No heterogeneity was found between trials $\left(I^{2}=0 \%\right)$.

Three studies measured triglycerides (Djuric 2006; Maskarinec 1999; Smith-Warner 2000) and data were pooled from all three. Two trials measured triglycerides at 12 months (Djuric 2006; SmithWarner 2000) and one study at six months (Maskarinec 1999). Overall, there was a tendency for triglyceride levels to increase with the intervention, but this did not reach statistical significance (MD $0.10 \mathrm{mmol} / \mathrm{L}(95 \% \mathrm{Cl}-0.06$ to 0.27$)$ ) (Analysis 1.6$)$ (280 participants). Furthermore, no heterogeneity was found between trials $\left(\mathrm{I}^{2}=0 \%\right)$.

\section{Provision of fruit and vegetables to increase consumption}

Six trials examined the effects of provision of fruit and vegetables, four had a follow-up period of three months (Dichi 2011; Finley 2007; Fujioka 2006; Thies 2012), and two a follow-up period of over six months (Gardner 2007; Gravel 2009).

\section{Clinical Events}

None of the included studies provided clinical event data.

\section{Cardiovascular risk factors}

\section{Blood pressure}

Four of the five included studies measured blood pressure (Dichi 2011; Fujioka 2006; Gravel 2009; Thies 2012). One study reported medians and interquartile ranges suggesting the data were skewed (Dichi 2011), and authors of two studies were contacted for information on mean changes and variance but this was not forthcoming (Fujioka 2006; Gravel 2009). Two studies also did not provide information on effect size or statistical significance (Fujioka 2006; Gravel 2009)

Differences were seen for diastolic blood pressure in women with metabolic syndrome in both the intervention and control group $(P<0.05)$ (Dichi 2011) (30 participants) at 90 days. One study reported no effects on systolic (MD $1.00 \mathrm{mmHg}, 95 \% \mathrm{Cl} 0.45$ to 1.55 ) (Analysis 2.1) or diastolic blood pressure (MD $1.50 \mathrm{mmHg}, 95 \% \mathrm{Cl}$ 1.18 to 1.82 ) (Analysis 2.2) with the provision of fruit and vegetables to increase consumption (Thies 2012) (157 participants) at three months. The remaining two studies also reported no effects on blood pressure with the provision of fruit and vegetables to increase consumption (Fujioka 2006; Gravel 2009) (180 participants) at three months (Fujioka 2006) and six months (Gravel 2009).

\section{Lipid levels}

Three trials measured total cholesterol (Dichi 2011; Finley 2007; Thies 2012). One study measured this at 90 days (Dichi 2011) while the other two studies measured total cholesterol at three months (Finley 2007; Thies 2012). One study reported data in graphical form and found a statistically significant reduction in total cholesterol $(P<0.014)$ for those who ate pinto beans (the intervention) compared with those who ate chicken soup (the comparison group) (Finley 2007) (80 participants) at three months. For the pooled analysis (187 participants), moderate heterogeneity was found between studies $(12=51 \%)$ so a random-effects meta-analysis was performed. From the pooled analysis, fruit and vegetable provision was found to lower total cholesterol slightly (MD $-0.10 \mathrm{mmol} /$ $\mathrm{L}, 95 \% \mathrm{Cl}-0.24$ to 0.04 ) but this was not statistically significant (Analysis 2.3). Results were similar for the fixed-effect model but the random-effects results were reported as the effect estimate is more conservative with wider confidence intervals.

Four trials measured LDL cholesterol (Dichi 2011; Finley 2007; Gardner 2007; Thies 2012). One study reported the data in graphical form and found a reduction in LDL cholesterol with the intervention ( $P<0.5$, Finley 2007) (80 participants) at three months. The other three studies could not be combined as there was substantial heterogeneity between trials $\left(I^{2}=59 \%\right)$ (Analysis 2.4) (284 participants). One study showed a significant reduction in LDL cholesterol with the intervention (MD $-0.09 \mathrm{mmol} / \mathrm{L}, 95 \% \mathrm{Cl}$ -0.12 to -0.06 ) (Thies 2012) at three months while the two remaining studies found fruit and vegetable provision to have no effect on LDL cholesterol (Dichi 2011; Gardner 2007) at 90 days (Dichi 2011) and at six months (Gardner 2007).

All six studies examined the effects of provision of fruit and vegetables on $\mathrm{HDL}$ cholesterol. Usable data were not available for three studies, two reported that they found no significant effects of the intervention on HDL cholesterol levels (Fujioka 2006; Gravel 2009) at three months (Fujioka 2006) and six months (Gravel 2009), whereas the third study found significantly reduced HDL cholesterol levels (Finley 2007) at three months. Data for the remaining three studies could not be pooled as there was significant heterogeneity present $\left(I^{2}=90 \%\right)$ ( (Analysis 2.5) (284 participants). One study showed a significant increase in HDL cholesterol with soy (MD $0.17,95 \% \mathrm{Cl} 0.02$ to 0.32 ) (Dichi 2011) at 90 days and the second study with raw garlic (MD $0.08 \mathrm{mmol} / \mathrm{L}, 95 \% \mathrm{Cl}$ 0.00 to 0.16 ) (Gardner 2007) at six months. The third study showed a significant decrease in $\mathrm{HDL}$ cholesterol (MD $-0.06 \mathrm{mmol} / \mathrm{L}, 95 \% \mathrm{Cl}$ -0.08 to -0.04 ) (Thies 2012) at three months.

Similarly, all six trials measured triglycerides and data were pooled for three trials with useable data (Analysis 2.6). For these three trials, triglycerides were measured at three months (Finley 2007; Fujioka 2006) and six months (Gravel 2009). No heterogeneity was found between trials $(12=0 \%)$. Overall, there was no effect of the intervention on triglyceride levels (MD $-0.01 \mathrm{mmol} / \mathrm{L}(95 \% \mathrm{Cl}$ -0.03 to 0.01 )) (284 participants). No effects on triglycerides were reported in the remaining three trials that did not contribute to the meta-analysis (Finley 2007; Fujioka 2006; Gravel 2009).

\section{Adverse effects}

Adverse effects of the provision of fruit and vegetables were noted in two of the six included studies (Fujioka 2006; Gardner 2007). One reported that there were few adverse effects over three months 
(Fujioka 2006). The second study reported that no serious adverse effects occurred over six months (Gardner 2007) but that bad breath and body odour were reported in 57\% of those receiving the intervention (raw garlic) and flatulence was reported by three participants in the intervention group and one participant in the control group.

One of the three studies examining the effects of dietary advice to increase fruit and vegetable consumption examined adverse effects (Smith-Warner 2000).This study reported significantly increased bowel movements from 9.2 to 10.0 a week with the intervention and significantly more flatulence $(P=0.01)$, but this did not persist after three months.

\section{Costs}

None of the included studies provided data on costs.

\section{DISCUSSION}

\section{Summary of main results}

Ten trials which randomised 1730 participants were identified from the 298 papers screened. None of the trials reported clinical endpoints. Six of these 10 trials examined the provision of fruit and vegetables to increase consumption. From these, there was no strong evidence in favour of the effects of fruit and vegetable provision on CVD risk factors, however, the trials were heterogeneous, and short term.

Four trials examined dietary advice to increase fruit and vegetable consumption. From these trials, there was some evidence of favourable effects of dietary advice to increase fruit and vegetable consumption on blood pressure and to a lesser extent on LDL cholesterol at six months. However, it should be noted that few trials contributed to each analysis.

\section{Overall completeness and applicability of evidence}

This review included adult participants who were at varying levels of CVD risk and included both men and women. The majority of trials were conducted in developed countries. None of the included studies examined our primary outcomes as trials were relatively short term and participants were relatively healthy. We were also unable to examine the effects of baseline CVD risk or the intensity of interventions due to the limited number of included studies.

The effectiveness of the provision of fruit and vegetables could not be rigorously assessed since only two trials (229 participants) assessed cardiovascular risk factors at six months.The remaining four were shorter term so it is unclear whether any effects of the intervention could be sustained. In most cases, these trials examined one type of fruit or vegetable so generalisability is limited.

Similarly, few trials were identified examining the effectiveness of dietary advice to increase fruit and vegetable consumption. Three trials were found with six months or more follow-up with 924 participants randomised.

For both trials of provision of fruit and vegetables and dietary advice to increase consumption of fruit and vegetables there was considerable variability in the interventions, the participants recruited and the outcomes measured. For dietary advice trials, there may have also been differences in the serving sizes recommended within interventions, however, the definition of portion size was not provided in these trials and so it is not possible to tell.

\section{Quality of the evidence}

Overall, the studies included in this review were at some risk of bias and results should be treated with some caution. In seven of the 10 included studies the methods of random sequence generation were not stated, while in nine of the included trials details of allocation concealment were not given. Eight of the 10 included studies did not state if the participants and personnel were blinded and five studies did not report the blinding of outcome assessment. Blinding of participants and personnel is difficult if not impossible for behavioural interventions, but outcome assessment can be blinded. Risk of bias due to incomplete outcome data was found to be low in four studies and unclear in six studies, and bias due to selective reporting was regarded as high in two studies, low in three and unclear in the remainder. In all studies there was insufficient information to judge the risk of other biases.

\section{Potential biases in the review process}

We conducted a comprehensive search across major databases for interventions to increase fruit and vegetable consumption. We also screened systematic review reference lists and contacted trial authors where necessary. However, from corresponding with authors we did not receive further unreported data from two trials which limited our analyses. Screening, inclusion and exclusion and data abstraction were conducted in duplicate by two review authors independently. Data entry and analyses were carried out by two review authors.

Our decision to restrict this review to interventions only investigating fruit and vegetables avoided the potential confounding effects of other behavioural interventions on our outcomes e.g. those involving other dietary interventions, exercise or weight loss, but limited the number of studies eligible for inclusion. By restricting our inclusion criteria in this way, we excluded some large trials, notably the Womens Health Initiative (WHI) trial, which examined also the effects of reducing dietary fat and increasing grain consumption, as well as increasing fruit and vegetable intake (WHI). The WHI trial randomised over 8000 postmenopausal women, follow-up is reported over eight years and showed no effect of dietary modification including fruit and vegetable intake on cardiovascular disease clinical endpoints. One could argue that assuming reducing dietary fat and increasing grain consumption is not actively harmful, then this trial demonstrates no effect of fruit and vegetable intake on CVD events, at least in this population of well nourished, middle-aged women.

Furthermore, limitations in reporting methodological quality, an unclear risk of bias in most trials and sparse or no data for primary and secondary outcomes mean that the findings of this review should be treated with caution due to the small number of trials on which they are based.

\section{Agreements and disagreements with other studies or reviews}

To our knowledge, no other systematic review involving only randomised controlled trials has been conducted solely to examine the effects of increasing fruit and vegetable consumption in adults for the primary prevention of CVD. Other systematic reviews have 
looked at dietary advice for the primary prevention of CVD that includes increasing fruit and vegetable consumption, but also other dietary modifications (Brunner 2007). Dietary advice was found to be effective at increasing fruit and vegetable consumption in the review by Brunner et al, but we cannot directly compare the effects on CVD risk factors between the two reviews as changes may be due to other dietary modifications such as decreasing fat, salt or increasing dietary fibre. All of the trials of dietary advice to increase consumption of fruit and vegetables are included in both reviews. CVD risk factors were not measured in the review by Pomerleau et al so again we are unable to compare our findings (Pomerleau 2005). These authors showed that interventions designed to increase fruit and vegetable consumption increased fruit and vegetable intake by $\sim 0.1$ to 1.4 servings per day. Provision of fruit and vegetables is more difficult to compare with other studies as most of the studies we found focus on one particular fruit or vegetable, thereby limiting the findings. Other systematic reviews have looked at increasing fruit and vegetable consumption in children (Wolfenden 2012). The findings showed that there were few effective interventions aimed at improving fruit and vegetable consumption in children aged five years and under. Other systematic reviews are ongoing in different populations (Ganann 2010).

The current systematic review found few trials on interventions focused solely on increasing the consumption of fruit and vegetables in the absence of other dietary modifications, which limits the findings. In the four trials we found on dietary advice to increase fruit and vegetable consumption, favourable effects were seen on blood pressure and to a lesser extent lipid levels.

\section{AUTHORS' CONCLUSIONS}

\section{Implications for practice}

Very few trials met the inclusion criteria for our review and none reported our primary outcome. Our strict inclusion criteria was designed to look specifically at the effects of increased fruit and vegetable consumption in the absence of other dietary interventions, but this limited the number of trials included and excluded notably one large trial reporting clinical endpoints
(WHI). In our review, favourable effects were seen for outcomes of cardiovascular risk factors in the four trials of dietary advice to increase the consumption of fruit and vegetables, which is promising, but more trials are needed to confirm this and to examine effects over the longer term. Results from trials of the provision of single fruits or vegetables were more limited. Given the limited evidence to date, our review does not make any recommendations about changing practice. Current guidance recommends consumption of at least five portions of fruit and vegetables per day.

\section{Implications for research}

There is a lack of randomised controlled trials examining solely the effects of advice to consume more fruit and vegetables and the provision of fruit and vegetables to increase consumption for the primary prevention of CVD. This is surprising given that national and international guidelines recommend the consumption of at least five portions of fruit and vegetables per day. In particular, and most importantly, there is a shortage of randomised controlled trials that look at the effects of interventions to solely increase fruit and vegetable consumption over the longer term to determine the sustainability of such behavioural change, and to examine effects on our primary outcome CVD events. Other large trials of multifactorial dietary interventions including increased fruit and vegetable consumption have shown no benefits of the intervention on CVD clinical events (WHI), and this finding may hold true also for interventions aimed solely at increasing fruit and vegetable consumption, assuming the other components of the dietary intervention did no harm. This evidence is however limited to middle-aged women and more research is needed in other groups. Furthermore, we found no trials reporting economic evaluations of interventions to increase fruit and vegetable consumption.

\section{ACKNOWLEDGEMENTS}

We are grateful to Nicole Martin and Jo Abbot for conducting the searches for this review. We would also like to acknowledge Dr Dichi for providing additional data from his trial (Dichi 2011). 


\section{R E F E R E N C E S}

\section{References to studies included in this review}

Dichi 2011 \{published and unpublished data\}

Dichi, IS. Ingestion of soybean or fish increases adiponectin and nitric oxide levels and decreases blood pressure in women with metabolic syndrome. In: Journal of Diabetes. Vol. Conference (var.pagings): April. 2011.

\section{Djuric 2006 \{published data only\}}

Chen G, Heilbrun LK, Venkatramanamoorthy R, Maranci V, Redd JN, Klurfeld DM et al. Effects of low-fat and/or high-fruitand-vegetable diets on plasma levels of 8-isoprostane-F2alpha in the Nutrition and Breast Health study. Nutrition and Cancer 2004;50(2):155-60.

Djuric Z, Chen G, Ren J, Venkatramanamoorthy R, Covington $\mathrm{CY}$, Kucuk $\mathrm{O}$ et al. Effects of high fruit-vegetable and/or low-fat intervention on breast nipple aspirate fluid micronutrient levels. Cancer Epidemiology, Biomarkers and Prevention 2007;16(7):1393-9.

* Djuric Z, Ren J, Mekhovich O, Venkatranamoorthy R, Heilbrun LK. Effects of high fruit-vegetable and/or low-fat intervention on plasma micronutrient levels. Journal of the American College of Nutrition 2006;25(3):178-87.

\section{Finley 2007 \{published data only\}}

Finley JW, Burrell JB, Reeves PG. Pinto bean consumption changes SCFA profiles in fecal fermentations, bacterial populations of the lower bowel, and lipid profiles in blood of humans. Journal of Nutrition 2007;137(11):2391-8.

Fujioka 2006 \{published data only\}

Fujioka KG. The effects of grapefruit on weight and insulin resistance: Relationship to the metabolic syndrome. Journal of Medicinal Food 2006;9(1):49-54.

\section{Gardner 2007 \{published data only\}}

Gardner CD, Lawson LD, Block E, Chatterjee LM, Kiazand A, Balise RR et al. Effect of raw garlic vs commercial garlic supplements on plasma lipid concentrations in adults with moderate hypercholesterolemia: a randomized clinical trial. Archives of Internal Medicine 2007;167(4):346-53.

Gravel 2009 \{unpublished data only\}

Gravel K, Lemieux S, Asselin G, Lemay A, West G, Forest JC et al. Does legumes consumption in a real life context can improve components of metabolic syndrome?. A randomized controlled trial. Journal of Diabetes Conference (var.pagings): April 2009;1:A277.

\section{John 2002 \{published data only\}}

John JH, Ziebland S, Yudkin P, Roe LS, Neil HA. Effects of fruit and vegetable consumption on plasma antioxidant concentrations and blood pressure: a randomised controlled trial. Lancet 2002;359(9322):1969-74.

\section{Maskarinec 1999 \{published data only\}}

Maskarinec G, Chan CL, Meng L, Franke AA, Cooney RV. Exploring the feasibility and effects of a high-fruit and - vegetable diet in healthy women. Cancer Epidemiology and Biomarkers \& Prevention 1999;8(10):919-24.

Smith-Warner 2000 \{published data only\}

Smith-Warner SA, Elmer PJ, Tharp TM, Fosdick L, Randall B, Gross $M$ et al. Increasing vegetable and fruit intake: randomized intervention and monitoring in an at-risk population. Cancer Epidemiology and Biomarkers \& Prevention 2000;9(3):307-17.

Thies 2012 \{published data only\}

Thies F, Masson LF, Rudd A, Vaughan N, Tsang C, Brittenden J et al. Effect of a tomato-rich diet on markers of cardiovascular disease risk in moderately overweight, disease-free, middleaged adults: a randomized controlled trial. The American Journal of Clinical Nutrition 2012;95(5):1013-22.

\section{References to studies excluded from this review}

Ali 1995 \{published data only\}

Ali MT. Consumption of a garlic clove a day could be beneficial in preventing thrombosis. Prostaglandins Leukotrienes and Essential Fatty Acids 1995;53(3):211-2.

Appel 2000 \{published data only\}

Appel LJ, Miller ER 3rd, Jee SH, Stolzenberg-Solomon R, $\mathrm{Lin} \mathrm{PH}$, Erlinger $\mathrm{T}$ et al. Effect of dietary patterns on serum homocysteine: results of a randomized, controlled feeding study. Circulation 2000;102(8):852-7.

Beresford 2001 \{published data only\}

Beresford S, Thompson B, Feng Z, Christianson A, McLerran D, Patrick D. Seattle 5 a Day worksite program to increase fruit and vegetable consumption. Preventive Medicine 2001;32(3):230-8.

\section{Blum 2007 \{published data only\}}

Blum A, Monir M, Khazim K, Peleg A, Blum N. Tomatorich (Mediterranean) diet does not modify inflammatory markers. Clinical \& Investigative Medicine - Medecine Clinique et Experimentale 2007;30(2):E70-E74.

\section{Broekmans 2000 \{published data only\}}

Broekmans WMR. Fruits and vegetables increase plasma carotenoids and vitamins and decrease homocysteine in humans. Journal of Nutrition 2000;130(6):1578-83.

\section{DASH 1995 \{published data only\}}

* Sacks FM, Obarzanek E, Windhauser MM, Svetkey LP, Vollmer WM, McCullough $M$ et al. Rationale and design of the Dietary Approaches to Stop Hypertension trial (DASH). A multicenter controlled-feeding study of dietary patterns to lower blood pressure. Annals of Epidemiology 1995;5(2):108-18.

Yarmohammadi H, Turban SI, Appel L. Effect of dietary patterns on blood pressure variability. Journal of the American College of Cardiology 2012;59:E1631.

\section{Fielding 2005 \{published data only\}}

Fielding JM, Rowley KG, Cooper P, O' Dea K. Increases in plasma lycopene concentration after consumption of tomatoes 
cooked with olive oil. Asia Pacific Journal of Clinical Nutrition 2005;14(2):131-6.

\section{Fuemmeler 2006 \{published data only\}}

Fuemmeler BF, Masse LC, Yaroch A, Resnicow K, Campbell MK, Carr $\mathrm{C}$ et al. Psychosocial mediation of fruit and vegetable consumption in the body and soul effectiveness trial. Health Psychology 2006;25(4):474-83.

\section{Havas 2003 \{published data only\}}

Havas S, Anliker J, Breenberg D, Block G, Block T, Blik C et al. Final results of the Maryland WIC Food for life programme. Preventive Medicine 2003;37(5):406-16.

Lehtonen 2010 \{published data only (unpublished sought but not used)\}

Lehtonen HM, Suomela JP, Tahvonen R, Vaarno J, Venojarvi M, Viikari J et al. Berry meals and risk factors associated with metabolic syndrome. European Journal of Clinical Nutrition 2010;64(6):1-8.

\section{Lutz 1999 \{published data only\}}

Lutz SF, Ammerman AS, Atwood JR, Campbell MK, DeVellis RF, Rosamond WD. Innovative newsletter interventions improve fruit and vegetable consumption in healthy adults. Journal of the American Dietetic Association 1999;99(6):705-9.

\section{Nomikos 2007 \{published data only\}}

Nomikos TD. Boiled wild artichoke reduces postprandial glycemic and insulinemic responses in normal subjects but has no effect on metabolic syndrome patients. Nutrition Research 2007;27(12):741-9.

\section{Porrini 2011 \{unpublished data only\}}

Porrini M. Effect of wild blueberry intake on reduction of cardiovascular risk factors. ISRCTN47732406.

\section{Rock 2001 \{published data only\}}

Rock CL, Moskowitz A, Huizer B, Saenz CC, Clark JT, Daly TL et al. High vegetable and fruit diet intervention in premenopausal women with cervical intraepithelial neoplasia. Journal of the American Dietetic Association 2001;101(10):1167-74.

\section{Singh 1992 \{published data only\}}

Singh R, Rastogi S, Singh R, Ghosh S, Niaz M. Effects of guava intake on serum total and high-density lipoprotein cholesterol levels and on systemic blood pressure. American Journal of Cardiology 1992;70(15):1287-91.

\section{Sorensen 1999 \{published data only\}}

Sorensen G, Stoddard A, Peterson K, Cohen N, Hunt MK, Stein $E$ et al. Increasing fruit and vegetable consumption through worksites and families in the treatwell 5-a-day study. American Journal of Public Health 1999;89(1):54-60.

\section{Staten 2004 \{published data only\}}

Staten LK, Gregory-Mercado KY, Ranger-Moore J, Will JC, Giuliano AR, Ford ES et al. Provider counseling, health education and community health workers: the Arizona WISEWOMAN project. Journal of Women's Health 2004;13(5):547-56.

\section{Steptoe 2004 \{published data only\}}

Steptoe A, Perkins-Porras L, Hilton S, Rink E, Cappuccio FP. Quality of life and self-rated health in relation to changes in fruit and vegetable intake and in plasma vitamins $C$ and $E$ in a randomised trial of behavioural and nutritional education counselling. British Journal of Nutrition 2004;92:177-84.

\section{Svetkey 2003 \{published data only\}}

Svetkey LP, Harsha DW, Vollmer WM, Stevens VJ, Obarzanek E, Elmer PJ et al. Premier: a clinical trial of comprehensive lifestyle modification for blood pressure control: rationale, design and baseline characteristics. Annals of Epidemiology 2003 ;13(6):462-71.

Takai 2003 \{published data only\}

Takai M, Suido H, Tanaka T, Kotani M, Fujita A, Takeuch A et al. LDL-cholesterol-lowering effect of a mixed green vegetable and fruit beverage containing broccoli and cabbage in hypercholesterolemic subjects. Rinsho Byori - Japanese Journal of Clinical Pathology 2003;51(11):1073-83.

Thomson 2011 \{unpublished data only\}

Thomson C. A grapefruit feeding trial in healthy, overweight adults. NCT01452841.

\section{Verlangieri 1985 \{published data only\}}

Verlangieri AJ, Kapeghian JC, el-Dean S, Bush M. Fruit and vegetable consumption and cardiovascular mortality. Medical Hypotheses 1985;16(1):7-15.

\section{WHI \{published data only\}}

Howard BV, Van Horn L, Hsia J, Manson JE, Stefanick ML, Wassertheil-Smoller S et al. Low-fat dietary pattern and risk of cardiovascular disease: the Women's Health Initiative Randomized Controlled Dietary Modification Trial. JAMA 2006;295(6):655-66.

* White E, Shattuck AL, Kristal AR, Urban N, Prentice RL, Henderson MM et al. Maintenance of a low-fat diet: follow-up of the Women's Health Trial. Cancer Epidemiology, Biomarkers and Prevention 1992;1(4):315-23.

\section{Winham 2007 \{published data only\}}

Winham DM, Hutchins AM, Johnston CS. Pinto bean consumption reduces biomarkers for heart disease risk. Journal of the American College of Nutrition 2007;26(3):243-9.

\section{References to studies awaiting assessment}

\section{George 2009 \{published data only\}}

George TW, Niwat C, Waroonphan S, Gordon MH, Lovegrove JA, Paterson E. Effects of chronic and acute fruit and vegetable juice consumption on cardiovascular disease risk factors. li International Symposium on Human Health Effects of Fruits and Vegetables: Favhealth 2007 2009;841:201-6.

\section{Groen 1952 \{published data only\}}

Groen J, Tjiong BK. The influence of nutrition, individuality and some other factors, including various forms of stress, on the serum cholesterol; an experiment of 9 months' duration in 60 normal human volunteers. Voeding 1952;13(11):556-87. 
Teeple (2011) \{unpublished data only\}

Teeple JA, Kaume L, Gbur E, Devareddy L. Antioxidantrich berries reduce inflammation and oxidative stress in postmenopausal smokers. FASEB Journal 2011;25:339.3.

\section{Wallace 2012 \{published data only\}}

Wallace IR, McEvoy CT, Amill LL, Ennis CN, Bell PM, Hunter SJ et al. Dose-response effect of fruit and vegetables on insulin resistance in healthy people who are overweight and at high risk of cardiovascular disease: A randomised controlled trial. Diabetes 2012;61:A187.

\section{References to ongoing studies}

\section{Wang 2011 \{published data only\}}

Wang L, Bordi PL, Rothblat GH, Sankaranarayanan S, Fleming JA, Kris-Etherton PM. The effect of one avocado per day on established and emerging cardiovascular disease (CVD) risk factors: study design. The FASEB Journal 2011;25:971.5.

\section{Additional references}

\section{Agudo 2004}

Agudo A. Measuring intake of fruit and vegetables. Background paper for Joint FAO/WHO Workshop on Fruit and Vegetables for Health. 1-3 September 2004. Kobe, Japan.

\section{Ajzen 1991}

Ajzen I. The theory of planned behavior. Organizational Behavior and Human Decision Processes 1991;50(2):179-211.

\section{Ammerman 2002}

Ammerman AS, Lindquist $\mathrm{CH}$, Lohr KN, Hersey J. The efficacy of behavioural interventions to modify dietary fat and fruit and vegetable intake: a review of the evidence. Preventive Medicine 2002;35(1):25-41.

\section{Anderson 1994}

Anderson AS, Marshall D, Lean ME, Foster A. Five a day? Factors affecting fruit and vegetable consumption in Scotland. Nutrition and Food Sciences 1994;5:14-6.

\section{Asgard 2007}

Asgard R, Rytter E, Basu S, Abramsson-Zettererg L, Moller L, Vessby B. High intake of fruit and vegetables is related to low oxidative stress and inflammation in a group of patients with type 2 diabetes. Scandinavian Joutnal of Food \& Nutrition 2007;51(4):149-58.

\section{Bandura 1986}

Bandura A. Social Foundations of Thought and Action: A Socia Cognitive Theory. Englewood Cliffs, New Jersey: Prentice Hall, 1986.

\section{Bazzano 2002}

Bazzano LA, He J, Ogden LG, Loria CM, Vupputuri S, Myers L et al. Friut and vegetable intake and risk of cardiovascular disease in U.S Adults: the first National Health and Nutrition Examination Survey Epidemiologic Follow-up Study. American Journal of Clinical Nutrition 2002;76(1):93-9.

\section{Begg 2007}

Begg S, Vos T, Barker B, Stevenson C, Stanley L, Lopez A. The burden of disease and injury in Australia 2003. Cat. no. PHE 82. Canberra: AlHW 2007.

\section{Blanchflower 2012}

Blanchflower DG, Oswald AJ, Stewart-Brown S. Is psychological well-being linked to the consumption of fruit and vegetables? The Warwick Economics Research Paper Series (TWERPS) 996, University of Warwick, Department of Economics. 2012.

\section{Brug 1995}

Brug J, Debi S, van Assema P, Weijts W. Psychosocial determinants of fruit and vegetable consumption among adults: results of focus group interviews. Food Quality and Preference 1995;6(2):99-107.

\section{Brunner 2007}

Brunner E, Rees K, Ward K, Burke M, Thorogood M. Dietary advice for reducing cardiovascular risk. Cochrane Databaseof Systematic Reviews 2007;17(4):Art. No.: CD002128. DOI: 10.1002/14651858.CD002128.pub3.

\section{Burchett 2003}

Burchett $\mathrm{H}$. Increasing fruit and vegetable consumption among British primary schoolchildren: a review. Health Education 2003;103(2):99-109.

\section{Carter 2010}

Carter P, Gray LJ, Troughton J, Khunti K, Davies MJ. Fruit and vegetable intake and incidence of type 2 diabetes mellitus: systematic review and meta-analysis. BMJ 2010;341:c4229.

\section{Clark 1998}

Clark JE. Taste and flavour: their importance in food choice and acceptance. Proceedings of the Nutrition Society 1998;57:639-43.

\section{Contento 1995}

Contento I, Balch GI, Bronner YL, Lytle LA, Maloney SK, Olson CM et al. The effectiveness of nutrition education and implication for nutrition education policy, programs, and research: a review of research. Journal of Nutrition Education 1995;27:277-418.

\section{Dauchet 2006}

Dauchet L, Amouyel P, Hercberg S, Dallongeville J. Fruit and Vegetable Consumption and Risk of Cornary Heart Disease: A Meta-anlaysis of Cohort Studies. J Nutr 2006;136(10):2588-93.

\section{Department of Health 2010}

Department of Health (2010). 5 A DAY general information. Available at: http://webarchive.nationalarchives.gov.uk/ +/www.dh.gov.uk/en/Publichealth/Healthimprovement/ FiveADay/FiveADaygeneralinformation/DH_4002343. Accessed 27 October 2011

\section{Egger 1997}

Egger M, Davey Smith G, Schneider M, Minder C. Bias in meta-analysis detected by a simple graphical test. BMJ 1997;315:629-34. 


\section{Ganann 2010}

Ganann R, Fitzpatrick-Lewis D, Ciliska D, Dobbins M, Krishnaratne S, Beyers J et al. Community-based interventions for enhancing access to or consumption of fruit and vegetables (or both) among five to 18-year olds. Cochrane Database of Systematic Reviews 2010, Issue 8. Art. No: CD008644. [DOI: 10.1002/14651858.CD008644]

\section{Higgins 2011}

Higgins JPT, Green S (editors). Cochrane Handbook for Systematic Reviews of interventions Version 5.1.0. [updated March 2011]. Available from www.cochrane-handbook.org.

\section{Hooper 2007}

Hooper L. Primary Prevention of CVD: diet and weight loss. Clinical Evidence (online) 2007;0ct1:0219.

\section{Joshipura 2001}

Joshipura KJ, Hu FB, Manson JE, Stampfer MJ, Rimm EB, Speizer FE et al. The effect of fruit and vegetable intake on risk for coronary heart disease. Annals of Internal Medicine 2001;134(12):1106-14.

\section{Law 1999}

Law M, Wald N. Why heart disease mortality is low in France: the time lag explanation. BMJ 1999;318:1471-80.

\section{Lennernas 1997}

Lennernäs M, Fjellström C, Becker W, Giachetti I, Schmitt A, Remaut de Winter $A$ et al. Influences on food choice perceived to be important by nationally-representative samples of adults in the European union. European Journal of Clinical Nutrition 1997;51 (suppl) 2:S8-S15.

\section{Liu 2000}

Liu S, Manson JE, Lee IM, Cole SR, Hennekens CH, Willett WC et al. Fruit and vegetable intake and risk of cardiovascular disease: the Women's Health Study. American Journal of Clinical Nutrition 2000;72(4):922-8.

\section{Liu 2001}

Liu S, Lee IM, Ajani U, Cole SR, Buring JE, Manson JE. Intake of vegetables rich in carotenoids and risk of coronary heart disease in men: the Physician's Health Study. International Journal of Epidemiology 2001;30(1):130-5.

\section{Lock 2005}

Lock K, Pomerleau J, Causer L, Altmann D, McKee M. The global burden of disease attributable to low consumption of fruit and vegetables: implications for the global strategy on diet. Bulletin of the World Health Organization 2005;83:100-8.

\section{Maheswaran 2013}

Maheswaran H, Petrou S, Rees K, Stranges S. Estimating EQ-5D utility values for major health behavioural risk factors in England. Journal of Epidemiology and Community Health 2013;67(2):172-80. [DOI: 10.1136/jech-2012-201019]

\section{Miller 2000}

Miller He, Rigelhof F, Marquart L, Prakash A, Kanter M. Antioxidant content of whole grain breakfast cereal, fruit and vegetables. Journal of the American College of Nutrition 2000;19(3):312-9S

\section{Miller 2000a}

Miller M, Stafford H. An intervention portfolio to promote fruit and vegetable consumption; review of interventions. Melbourne, National Public Health Partnership 2000:1-32.

\section{Müller-Nordhorn 2008}

Müller-Nordhorn J, Binting S, Roll S, Willich S. An update on regional variation in cardiovascular mortality within Europe. European Heart Journal 2008;29:1316-26.

\section{Ness 1997}

Ness AR, Powles JW. Fruit and vegetables, and cardiovascular disease: a review. International Journal of Epidemiology 1997;26(1):1-13.

\section{NHS 2009}

NHS. Why 5 a Day? http://www.nhs.uk/Livewell/5ADAY/Pages/ Why5ADAY.aspx 2009.

\section{Ogden 2001}

Ogden J. Health Psychology: A Textbook. 2nd edition. Buckingham, Milton Keynes: Open University Press, 2001.

\section{Peterson 2002}

Peterson KE, Sorensen G, Pearson M, Hebert JR, Gottlieb BR, McCormick MC. Design of an intervention addressing multiple levels of influence on dietary and activity patterns of lowincome, postpartum women. Health Education Research 2002;17(5):531-40.

\section{Pollard 2002}

Pollard J, Kirk S, Cade J. Factors affecting food choices in relation to fruit and vegetable intake: a review. Nutrition Research Reviews 2002;15:373-87.

\section{Pomerleau 2004}

Pomerleau J, Lock K, McKee M. Effectiveness of interventions and programmes promoting Fruit and Vegetable intake: Background paper for the joint FAO/WHO workshop on fruit and vegetables for health. http://www.who.int/dietphysicalactivity/ publications/f\%26v_promotion_effectiveness.pdf 1-3 September 2004. Kobe, Japan.

\section{Pomerleau 2005}

Pomerleau J, Lock K, Knai C, McKee M. Interventions designed to increase adult fruit and vegetable intake can be effective: a systematic review of the literature. Journal of Nutrition 2005;135(10):2486-95.

\section{Prochaska 1984}

Prochaska JO, DiClimente CC. The Transtheoretical Approach: Crossing Traditional Boundaries of Therapy. Homewood, Illinois: Dow Jones Irwin, 1984

\section{Robinson 2008}

Robinson T. Applying the socio-ecological model to improving fruit and vegetable intake among low-income African Americans. Journal of Community Health 2008;33(6):395-406. 


\section{Rosenstock 1966}

Rosenstock IM. Why people use health services. Millbank Memorial Fund Quarterly 1966;44:94-124.

\section{Scarborough 2011}

Scarborough P, Morgan RD, Webster P, Rayner M. Differences in coronary heart disease,stroke and cancer mortality rates between England, Wales, Scotland andNorthern Ireland: the role of diet and nutrition. BMJ Open 2011;1:e000263:1-7.

\section{Suido 2002}

Suido H, Tanaka T, Tabei T, Takeuchi A, Okita M, Kishimoto $T$ et al. A mixed green vegetable and fruit beverage decreased the serum level of low-density lipoprotein cholesterol in hypercholesterolemic patients. Journal of Agricultural and Food Chemistry 2002;50(11):3346-50.

\section{Thompson 1999}

Thompson RL, Margetts BM, Speller VM, McVey D. The Health Eductaion Authority's health and lifestyle survey 1993: who are the low fruit and vegetable consumers? Journal of Epidemiology and Community Health 1999;53:294-9.

\section{Tobias 2001}

Tobias M. Ministry of Health. Ministry of Health, New Zealand, 2001.

\section{U.S. Department of Agriculture 2005}

US Department of Agriculture. Center for Nutrition Policy and Promotion. Washington DC: US Government Printing Office, 2005.

\section{CHARACTERISTICS OF STUDIES}

Characteristics of included studies [ordered by study ID]

\section{Van Duyn 2000}

Van Duyn MA, Pivonka E. Overview of the health benefits of fruit and vegetable consumption for the dietetics professional: Selected literature. Journal of the American Dietetic Association 2000;100(12):1511-21.

\section{WHO 2004}

Global Strategy on Diet, Physical Activity. World Health Organization. http://www.who.int/dietphysicalactivity/strategy/ eb11344/strategy_english_web.pdf 2004:1-19.

\section{WHO 2011}

Cardiovascular Diseases (CVDs). World Health Organization. http://www.who.int/mediacentre/factsheets/fs317/en/ index.html September 2011;Fact Sheet Number 317.

\section{Wolfenden 2012}

Wolfenden L, Wyse RJ, Britton BI, Campbell KJ, Hodder RK, Stacey FG et al. Interventions for increasing fruit and vegetable consumption in children aged 5 years and under. Cochrane Database of Systematic Reviews 2012, Issue 11. Art. No: CD008552. [DOI: 10.1002/14651858.CD008552.pub2]

\section{Yusuf 2001}

Yusuf S, Reddy S, Ôunpuu S, Anand S. Global burden of cardiovascular diseases. Part II: variations in cardiovascular disease by specific ethnic groups and geographic regions and prevention strategies. Circulation 2001;104(23):2855-64.

* Indicates the major publication for the study

Dichi 2011

\section{Study characteristics}

Methods RCT (Parallel group design) involving provision of fruit and vegetables to increase consumption.

Participants

Sixty women with metabolic syndrome who were 47.9 (SD = 9.98) years old were recruited and randomised in to four arms - control group who maintained their usual diet; $25 \mathrm{~g} / \mathrm{d}$ of soy; $3 \mathrm{~g} / \mathrm{d}$ of fish oil n-3 fatty acids; or $3 \mathrm{~g} / \mathrm{d}$ of fish oil n-3 fatty acids plus $25 \mathrm{~g} / \mathrm{d}$ soy. Fifteen participants were randomised to receive $25 \mathrm{~g} / \mathrm{d}$ of soy and 15 participants were randomised to the control group.

Country of publication was Brazil.

Soy group: received $25 \mathrm{~g}$ of soy a day.

Control group: followed their usual diet.

The follow-up period was at the end of the intervention period of 90 days.

Outcomes Blood pressure and lipid levels

Notes and blood pressure for each point at which these were measured. Authors responded with all data requested. 
Dichi 2011 (Continued)

Risk of bias

\begin{tabular}{lll}
\hline Bias & Authors' judgement & Support for judgement \\
\hline $\begin{array}{l}\text { Random sequence genera- } \\
\text { tion (selection bias) }\end{array}$ & Unclear risk & Not stated \\
\hline $\begin{array}{l}\text { Allocation concealment } \\
\text { (selection bias) }\end{array}$ & Unclear risk & Not stated \\
\hline $\begin{array}{l}\text { Blinding of participants } \\
\text { and personnel (perfor- } \\
\text { mance bias) }\end{array}$ & Unclear risk & Not stated \\
All outcomes & \\
\hline $\begin{array}{l}\text { Blinding of outcome as- } \\
\text { sessment (detection bias) } \\
\text { All outcomes }\end{array}$ & Unclear risk & Not stated \\
\hline $\begin{array}{l}\text { Incomplete outcome data } \\
\text { (attrition bias) } \\
\text { All outcomes }\end{array}$ & Unclear risk & Insufficient information to judge \\
\hline $\begin{array}{l}\text { Selective reporting (re- } \\
\text { porting bias) }\end{array}$ & Unclear risk & Insufficient information to judge \\
\hline \begin{tabular}{l} 
Other bias \\
\hline
\end{tabular} & Unclear risk & Insufficient information to judge \\
\hline
\end{tabular}

Djuric 2006

\section{Study characteristics}

Methods RCT on advice to increase fruit and vegetable consumption

Participants

Post-menopausal women who were 21-50 years old were recruited by community advertisements. One hundred and twenty-two women were randomly assigned in a $2 \times 2$ factorial design to four arms - the control group; low-fat diet; high fruit and vegetable diet; a combination of low-fat and high fruit and vegetables diet.

Inclusion criteria: at least one first degree relative with breast cancer, current benign mammogram or breast exam with follow-up recommendation of 1 year or more, no expected changes in the use of oral contraception, good general health, no expected changes in lifestyle during the study, fat intake of $25 \%$ of total energy or greater, fruit and vegetable intake of five or fewer servings per day.

Exclusion criteria: those taking supplements containing more than $150 \%$ of RDA's for vitamins and minerals.

Twenty-seven participants were randomised to receive the fruit and vegetables diet and twenty participants were randomised to receive the control diet. The country of publication was the U.S.A. trained dietician, then monthly, and monthly group meetings for the intervention period of 12 months. The goal for the high F\&V arm was to increase F\&V to 9 servings/day in a specified variety to increase carotenoid intake - 1 serving of a dark green vegetable high in lutenin, 1 serving of a dark orange vegetable high in a-carotene, 1 serving of a red product high in lycopene, 2 servings of other vegetables, 2 servings of vitamin C rich fruits, 2 servings of other fruits (1 serving defined as approximately $60 \mathrm{kcal}$ for 
fruit and $25 \mathrm{kcal}$ for most vegetables). Monthly meetings provided additional education on a variety of topics consistent with their dietary assignment.

Control group: no dietary counselling and were told they should continue their usual diet. They received a one page daily food guide pyramid as a guide for healthy eating but this was not discussed. Follow-up was at 12 months.

\begin{tabular}{ll}
\hline Outcomes $\quad$ Lipid levels \\
\hline Notes
\end{tabular}

\section{Risk of bias}

\begin{tabular}{lll}
\hline Bias & Authors' judgement & Support for judgement \\
\hline $\begin{array}{l}\text { Random sequence genera- } \\
\text { tion (selection bias) }\end{array}$ & Unclear risk & Randomisation method not stated \\
\hline $\begin{array}{l}\text { Allocation concealment } \\
\text { (selection bias) }\end{array}$ & Unclear risk & Not stated \\
\hline
\end{tabular}

Blinding of participants High risk Not stated but impossible to blind participants and personnel to advice
and personnel (perfor-
mance bias)

Blinding of outcome as- Low risk Laboratory personnel were blinded to diet arm assignment

sessment (detection bias)

All outcomes

\begin{tabular}{|c|c|c|}
\hline $\begin{array}{l}\text { Incomplete outcome data } \\
\text { (attrition bias) } \\
\text { All outcomes }\end{array}$ & Unclear risk & $\begin{array}{l}\text { Intention-to-treat analysis conducted but no reasons for loss to follow-up re- } \\
\text { ported }\end{array}$ \\
\hline
\end{tabular}

\begin{tabular}{lll}
\hline $\begin{array}{l}\text { Selective reporting (re- } \\
\text { porting bias) }\end{array}$ & Unclear risk & Insufficient information to judge \\
\hline Other bias & Unclear risk & Insufficient information to judge \\
\hline
\end{tabular}

Finley 2007

\section{Study characteristics}

Methods RCT involving the provision of fruit and vegetable to increase consumption

Participants
Men and women aged 18-55 years who were either pre-metabolic (defined as a waist circumference of $\geq 96.5 \mathrm{~cm}$ for men and $\geq 88.9 \mathrm{~cm}$ for women and at least one of the following: serum $\mathrm{HDL}-\mathrm{C}<55 \mathrm{mg} / \mathrm{dL}$; serum TG between 150 and $199 \mathrm{mg} / \mathrm{dL}$; fasting blood glucose between 100 and $125 \mathrm{mg} / \mathrm{dL}$; or BP be- tween $120 / 85$ and $140 / 85 \mathrm{mmHg}$.) or healthy were recruited locally by newspaper, radio, TV or Internet advertisements. Eighty participants were randomly assigned to two arms - the provision of beans or chicken soup.
Inclusion criteria were: waist circumference for women of $88.9 \mathrm{~cm}$ or above and for men of $96.5 \mathrm{~cm}$ or above. Pre-MetSyn patients also had to have at least 1 of the following - serum HDL-C $<55 \mathrm{mg} / \mathrm{dL}$, serum TG between $150-199 \mathrm{mg} / \mathrm{dL}$, fasting blood glucose between 100 and $125 \mathrm{mg} / \mathrm{dL}$ or BP between $120 / 85$ and $140 / 85 \mathrm{~mm} \mathrm{Hg}$. Healthy participants had values in the normal parameters.


Finley 2007 (Continued)

Exclusion criteria - those with a possible need for medical attention and those who had taken antibiotics within 6 months of the start of the study.

Forty participants were randomised to receive beans and forty were randomised to receive chicken noodle soup. Participants lived at home and consumed their own self-selected diets with restrictions that included no beans of any type except those provided by the study, no dietary supplements, no preor probiotic foods or supplements, and no prescription or over-the-counter medication to reduce intestinal gases.

Country of publication was the U.S.A.

Interventions Participants were asked to add one of four different bean or soup entrees per day to their normal diet. The entrees included with either beans or soup prepared by the Grand Forks Human Nutrition Research Centre.

Bean entree group: standard serving of cooked pinto beans ( $130 \mathrm{~g}$ or $1 / 2$ cup) canned by Bush Brothers

Soup group: chicken soup entree that was isonitrogenous and isocaloric as near as possible to the bean entree.

The follow-up period was at the end of the intervention period of 12 weeks. This does not include the 4week equilibration period.

\begin{tabular}{ll}
\hline Outcomes & Lipid levels \\
\hline Notes & $\begin{array}{l}\text { Author contacted for extra information on numbers for lipid levels but the contact author had died and } \\
\text { the leading author did not reply. The leading author was contacted twice via email. }\end{array}$ \\
\hline
\end{tabular}

\section{Risk of bias}

\begin{tabular}{lll}
\hline Bias & Authors' judgement & Support for judgement \\
\hline $\begin{array}{l}\text { Random sequence genera- } \\
\text { tion (selection bias) }\end{array}$ & Unclear risk & Not enough information provided and randomisation method not stated \\
\hline $\begin{array}{l}\text { Allocation concealment } \\
\text { (selection bias) }\end{array}$ & Unclear risk & Not stated \\
\hline $\begin{array}{l}\text { Blinding of participants } \\
\text { and personnel (perfor- } \\
\text { mance bias) } \\
\begin{array}{l}\text { All outcomes } \\
\hline\end{array}\end{array}$ & Unclear risk & Not stated \\
\hline
\end{tabular}

\begin{tabular}{lll}
\hline $\begin{array}{l}\text { Blinding of outcome as- } \\
\text { sessment (detection bias) } \\
\text { All outcomes }\end{array}$ & Unclear risk & Not stated \\
\hline $\begin{array}{l}\text { Incomplete outcome data } \\
\text { (attrition bias) } \\
\text { All outcomes }\end{array}$ & Unclear risk & $\begin{array}{l}\text { No intention-to-treat analysis and little information on attrition rates. No rea- } \\
\text { sons given as to why participants dropped out or which group they were in. }\end{array}$ \\
\hline $\begin{array}{l}\text { Selective reporting (re- } \\
\text { porting bias) }\end{array}$ & High risk & $\begin{array}{l}\text { The numbers for lipid levels were not reported. Information on lipid levels } \\
\text { were provided in a graph but without precise numbers and only a P value. }\end{array}$ \\
\hline Other bias & Unclear risk & Insufficient information to judge \\
\hline
\end{tabular}


Fujioka 2006

\section{Study characteristics}

Methods RCT of the provision of fruit and vegetables to increase consumption

Participants

Obese male and female patients with a BMI between 30 and $40 \mathrm{~kg} / \mathrm{m}^{2}$ recruited from a single centre through advertisements and flyers in rooms of primary care physicians. Ninety-one participants were randomised to four arms - placebo capsules plus 7 ounces of apple juice; grapefruit capsules with 7 ounces of apple juice; 8 ounces of grapefruit juice with placebo capsules; and half a fresh grapefruit with placebo capsules.

Inclusion criteria: BMI between 30 and $40 \mathrm{~kg} / \mathrm{m} 2$, stable weight in a $3 \mathrm{~kg}$ range in 3 months prior to study enrolment, willing to eat grapefruit and avoid other citrus products.

Exclusion criteria: Type 1 or 2 diabetes, those who have had gastrointestinal surgery for obesity, moderate to severe gastrointestinal disorder, known liver disease, chronic renal disease or cardiovascular disease. Also, those using cholesterol medications, planning on changing smoking habits, or using medications known to interact with grapefruit.

Twenty-four participants were randomised to receive fresh grapefruit plus placebo capsules (18 women, 6 men; 16 Caucasian, 5 Black, 0 Asian, 2 Hispanic, 1 other; Mean BMI = 36.8 (5.55)) and twenty-two participants were randomised to receive the placebo capsules plus apple juice ( 20 women, 2 men;16 Caucasian, 4 Black, 0 Asian, 2 Hispanic, 0 other; Mean BMI = 34.5 (3.05)).

Country of publication was the U.S.A.

Fresh grapefruit group: half a fresh grapefruit and a placebo capsule consumed 3 times a day before each meal. The fresh grapefruit was prepared by cutting it in half and then into four smaller pieces. The skin was pulled off and discarded and the rest of the grapefruit was eaten. Placebo group: placebo capsules plus 7 ounces $(207 \mathrm{~mL}$ ) of apple juice. The apple juice was reconstituted from frozen concentrate. The juice was supplied in individual servings and participants were provided with a 2-4 week supply at a time. All participants were encouraged to walk 20-30 minutes 3 or 4 times a week and consume their usual diet. The follow-up period was 12 weeks.

\begin{tabular}{ll}
\hline Outcomes & BP, lipid levels, adverse effects \\
\hline Notes & $\begin{array}{l}\text { Author contacted for extra data (standard deviations for BP and lipid levels at baseline and follow-up). } \\
\text { The author did respond but was unable to provide the data requested. }\end{array}$
\end{tabular}

\section{Risk of bias}

\begin{tabular}{lll}
\hline Bias & Authors' judgement & Support for judgement \\
\hline $\begin{array}{l}\text { Random sequence genera- } \\
\text { tion (selection bias) }\end{array}$ & Low risk & Random number table \\
\hline $\begin{array}{l}\text { Allocation concealment } \\
\text { (selection bias) }\end{array}$ & Unclear risk & Not stated \\
\hline
\end{tabular}

Blinding of participants Low risk States double-blind and uses a placebo

and personnel (perfor-

mance bias)

All outcomes

\begin{tabular}{ll}
\hline Blinding of outcome as- & Low risk States double blind \\
sessment (detection bias) & \\
All outcomes &
\end{tabular}

Incomplete outcome data Low risk Missing outcome data reasonable well balanced across groups
(attrition bias)


Fujioka 2006 (Continued)

All outcomes

Selective reporting (re- Low risk $\quad$ Primary and secondary outcomes clearly stated and reported.

porting bias)

Other bias Unclear risk Insufficient information to judge

Gardner 2007

\section{Study characteristics}

\begin{tabular}{|c|c|}
\hline Methods & RCT (parallel group design) involving the provision of fruit and vegetables for increased consumption \\
\hline \multirow[t]{3}{*}{ Participants } & $\begin{array}{l}\text { Adults aged 30-65 years recruited from the local community through advertisements with low-density } \\
\text { lipoprotein cholesterol (LDL-C) concentrations of } 130-190 \mathrm{mg} / \mathrm{dL} \text {, triglyceride levels less than } 250 \mathrm{mg} / \\
\mathrm{dL} \text { and a BMI of } 19-30 \text {. One hundred and ninety-two participants were randomised to four arms: raw } \\
\text { garlic; powdered garlic supplement; aged garlic extract supplement; and placebo. }\end{array}$ \\
\hline & $\begin{array}{l}\text { Exclusion criteria: Self-reported pregnancy, lactation, current smoking, prevalent heart disease, can- } \\
\text { cer, renal disorder, diabetes mellitus, use of lipid or antihypertensive medication. }\end{array}$ \\
\hline & $\begin{array}{l}\text { Forty-nine participants were randomised to receive raw garlic ( } 27 \text { women and } 22 \text { men; age } 40 \pm 9 \text {; non- } \\
\text { Hispanic white } 36 \text {, non-Hispanic black } 2 \text {, non-Hispanic Asian } 9 \text {, Hispanic } 1 \text {, other or not disclosed } 1 \text {; BMI } \\
25 \pm 3 \text { ) and forty-eight participants were randomised to receive the placebo ( } 24 \text { women and } 24 \text { men; } \\
\text { age } 49 \pm 9 \text {; non-Hispanic white } 31 \text {, non-Hispanic black } 0 \text {, non-Hispanic Asian } 7 \text {, Hispanic } 8 \text {, other or not } \\
\text { disclosed } 8 \text {; BMI } 25 \pm 3 \text { ). The country of publication was the U.S.A. }\end{array}$ \\
\hline
\end{tabular}

Interventions All groups consumed their intervention for 6 days a week for 6 months.

Raw garlic group: $4.0 \mathrm{~g}$ of blended raw garlic ( an averaged-sized clove crushed in a blender). Individually packaged aliquots of raw garlic were frozen at $-80^{\circ} \mathrm{C}$. After distribution these were thawed and mixed with condiments to be served in sandwiches. All sandwiches were prepared and distributed by the General Clinical Research Centre. Participants were instructed to heat bread or filling as desired but not to heat condiment as it contained the raw garlic. Twelve types of sandwiches were prepared that were designed to contain approximately $375 \mathrm{kcal}$ (mean and SD $373 \pm 21 \mathrm{kcal}$ ) with no more than $10 \%$ energy from saturated fat. Identical sandwiches were also served to those not in the raw garlic group but these did not have garlic mixed into the condiments.

Placebo group: 4-6 placebo tablets 6 days a week. The follow-up period was at the end of the intervention period of 6 months.

Outcomes Adverse effects and lipid levels

Notes

\section{Risk of bias}

\begin{tabular}{lll}
\hline Bias & Authors' judgement & Support for judgement \\
\hline $\begin{array}{l}\text { Random sequence genera- } \\
\text { tion (selection bias) }\end{array}$ & Low risk & $\begin{array}{l}\text { Research assistant drawing assignments in blocks of 24 without replacement } \\
\text { until all 24 allocations were assigned }\end{array}$ \\
\hline $\begin{array}{l}\text { Allocation concealment } \\
\text { (selection bias) }\end{array}$ & Low risk & Opaque envelopes \\
\hline
\end{tabular}


Gardner 2007 (Continued)
Blinding of participants
Low risk
Investigators and participants were blinded and personnel (performance bias)

All outcomes

\begin{tabular}{lll}
\hline $\begin{array}{l}\text { Blinding of outcome as- } \\
\text { sessment (detection bias) } \\
\text { All outcomes }\end{array}$ & Low risk & States that laboratory staff conducting analyses were blinded \\
\hline $\begin{array}{l}\text { Incomplete outcome data } \\
\begin{array}{l}\text { (attrition bias) } \\
\text { All outcomes }\end{array}\end{array}$ & Low risk & $\begin{array}{l}\text { Used intention-to-treat analysis and missing data were reasonably well bal- } \\
\text { anced between groups }\end{array}$ \\
\hline $\begin{array}{l}\text { Selective reporting (re- } \\
\text { porting bias) }\end{array}$ & Low risk & Primary and secondary outcomes clearly stated and reported. \\
\hline \begin{tabular}{l} 
Other bias \\
\hline
\end{tabular} & Unclear risk & Insufficient information to judge \\
\hline
\end{tabular}

Gravel 2009

\section{Study characteristics}

\begin{tabular}{|c|c|c|}
\hline Methods & \multicolumn{2}{|c|}{ RCT of the provision of fruit and vegetables to increase consumption } \\
\hline Participants & \multicolumn{2}{|c|}{$\begin{array}{l}\text { One hundred and thirty-four women with abnormal metabolic profile were recruited and randomised } \\
\text { to two arms - } 750 \mathrm{~mL} \text { of legumes per week or a control group who ate meals without legumes. Country } \\
\text { of publication was Canada. }\end{array}$} \\
\hline Interventions & \multicolumn{2}{|c|}{ Intervention group: $750 \mathrm{~mL}$ of legumes per week } \\
\hline & \multicolumn{2}{|c|}{ Control group: Control meals without legumes } \\
\hline & \multicolumn{2}{|c|}{ Follow-up period was at 24 weeks } \\
\hline Outcomes & \multicolumn{2}{|l|}{ BP and lipid levels } \\
\hline Notes & \multicolumn{2}{|c|}{$\begin{array}{l}\text { The author was contacted for extra information on the diet each group followed and for data on lipid } \\
\text { levels and blood pressure at each point measured. This was done twice via email. The author did not } \\
\text { respond. }\end{array}$} \\
\hline \multicolumn{3}{|l|}{ Risk of bias } \\
\hline Bias & Authors' judgement & Support for judgement \\
\hline $\begin{array}{l}\text { Random sequence genera- } \\
\text { tion (selection bias) }\end{array}$ & Unclear risk & Not stated \\
\hline $\begin{array}{l}\text { Allocation concealment } \\
\text { (selection bias) }\end{array}$ & Unclear risk & Not stated \\
\hline $\begin{array}{l}\text { Blinding of participants } \\
\text { and personnel (perfor- } \\
\text { mance bias) } \\
\text { All outcomes }\end{array}$ & Unclear risk & Not stated \\
\hline
\end{tabular}


Gravel 2009 (Continued)

Blinding of outcome as-
sessment (detection bias)

All outcomes

\begin{tabular}{lll}
\hline $\begin{array}{l}\text { Incomplete outcome data } \\
\text { (attrition bias) } \\
\text { All outcomes }\end{array}$ & Unclear risk & Insufficient information to judge \\
\hline $\begin{array}{l}\text { Selective reporting (re- } \\
\text { porting bias) }\end{array}$ & Unclear risk & Insufficient information to judge \\
\hline Other bias & Unclear risk & Insufficient information to judge \\
\hline
\end{tabular}

John 2002

\section{Study characteristics}

\begin{tabular}{|c|c|}
\hline Methods & RCT on advice to increase fruit and vegetable consumption. \\
\hline \multirow[t]{3}{*}{ Participants } & $\begin{array}{l}\text { Men and women aged } 25-64 \text { without serious chronic illnesses were recruited through the lists of two } \\
\text { general practices based in a healthcare centre. Seven hundred and twenty-nine participants were re- } \\
\text { cruited and randomised to two arms - advice to eat more fruit and vegetables ( } 5 \text { or more portions a } \\
\text { day) or to the control group who where asked to continue as usual. }\end{array}$ \\
\hline & $\begin{array}{l}\text { Exclusion criteria: cardiovascular diseases, gastrointestinal diseases, cancer, serious psychiatric disor- } \\
\text { ders, hypercholesterolaemia, patients who had undergone a recent traumatic event, those unable to } \\
\text { give informed consent, those using dietary supplements, pregnant, those attempting to conceive. }\end{array}$ \\
\hline & $\begin{array}{l}\text { Three hundred and sixty-four participants were randomised to receive fruit and vegetable advice (161 } \\
\text { women and } 183 \text { men; age } 45.7 \pm 10.1 \text {; current smoker } 16 \% \text {; male BMI } 26.1 \pm 3.2 \text {, female BMI } 25.4 \pm 4.6 \text { ) } \\
\text { and three hundred and sixty-five participants were randomised to continue as usual (191 women and } \\
155 \text { men; age } 46.0 \pm 10.1 \text {; current smoker } 17 \% \text {; male BMI } 26.7 \pm 3.6 \text {, female BMI } 25.3 \pm 4.6 \text { ). The country } \\
\text { of publication was the UK. }\end{array}$ \\
\hline
\end{tabular}

Interventions Health checks done at both visits by study research nurse for both groups of participants.

Fruit and vegetable advice group: Brief negotiation method in which research nurse introduced the benefits of eating more fruit and vegetables and presented a pictorial portion guide (portion was defined as $80 \mathrm{~g}$ serving). Method was used to encourage participants to identify specific and practical ways to eat more fruit and vegetables with the recommendation being the consumption of 5 or more portions a day. Participants were also provided with leaflets and other materials that addressed barriers in eating more fruit and vegetables and were asked to discuss any potential barriers. For those who thought that five portions a day was an unrealistic goal a lower target was set while those who already ate five or more portions of fruit and vegetables a day were given a leaflet on the importance of eating a variety of these. Each participant was also given an action plan, a magnet with the 5-a-day logo, a portion guide and a 2-week self-monitoring record book. The intervention took about 25 minutes. Two weeks after the intervention the research nurse telephoned participants to reinforce the message and discuss any problems. At three months a letter was sent to participants to reinforce the 5-a-day message along with a booklet of seasonal recipes and a strategy check list that suggested ways of incorporating extra portions into their diet.

Control group: received the same health check but the nurse explained that they would receive specific advice at their 6-month follow-up appointment. They were asked to carry on as usual. The follow-up period was 6 months. 
John 2002 (Continued)

Notes

\section{Risk of bias}

\begin{tabular}{|c|c|c|}
\hline Bias & Authors' judgement & Support for judgement \\
\hline $\begin{array}{l}\text { Random sequence genera- } \\
\text { tion (selection bias) }\end{array}$ & Low risk & Computer-generated randomisation list \\
\hline $\begin{array}{l}\text { Allocation concealment } \\
\text { (selection bias) }\end{array}$ & Unclear risk & Not stated \\
\hline $\begin{array}{l}\text { Blinding of participants } \\
\text { and personnel (perfor- } \\
\text { mance bias) } \\
\text { All outcomes }\end{array}$ & High risk & Not stated but impossible to blind participants and personnel to advice \\
\hline $\begin{array}{l}\text { Blinding of outcome as- } \\
\text { sessment (detection bias) } \\
\text { All outcomes }\end{array}$ & Low risk & Laboratories were masked to patient assignment \\
\hline $\begin{array}{l}\text { Incomplete outcome data } \\
\text { (attrition bias) } \\
\text { All outcomes }\end{array}$ & Low risk & $\begin{array}{l}\text { Used Intention-to-treat analysis. At baseline there were more men in the inter- } \\
\text { vention group than controls. Reasons for losses to follow-up reported }\end{array}$ \\
\hline $\begin{array}{l}\text { Selective reporting (re- } \\
\text { porting bias) }\end{array}$ & Unclear risk & Insufficient information to judge \\
\hline Other bias & Unclear risk & Insufficient information to judge \\
\hline
\end{tabular}

Maskarinec 1999

\section{Study characteristics}

Methods RCT of advice to increase fruit and vegetable consumption

Participants

Healthy women at least 35 years old were recruited from an ongoing observational study. Thirty-three women were randomised to 2 arms - an individualised dietary counselling program or to nutritional counselling based on published guidelines.

Inclusion criteria: Not taking a high dose vitamin supplement, be free from chronic conditions and have at least $50 \%$ mammographic densities, eating less than 5 daily servings of fruit and vegetables and be at least 35 years old.

Sixteen participants were randomised to receive individual counselling ( 47.6 years; 11 Asian, 3 Chinese, 8 Japanese, 1 Caucasian, 1 Afro-American) and seventeen participants were randomised to nutritional counselling (50.2 years: 11 Asian, 5 Chinese, 4 Caucasian, 3 Filipino, 3 Japanese, 1 Vietnamese). The country of publication was the U.S.A.

Interventions

Participants in both groups were instructed to consume the same number of calories as before and to avoid weight gain.

Individual Counselling Group: individualised dietary counselling program developed to incorporate at least 9 servings of fruits and vegetables daily. The emphasis was on achieving the goal of 9 servings with the following recommendations on the type of fruits and vegetables: 3 servings of vitamin C fruits, 1 other fruit, 1 tomato product, 1 dark green vegetable, 1 yellow-orange vegetable, and 2 other vegetables. The definition of a serving was the same as used by the United States Department of Agriculture: 1 
Maskarinec 1999 (Continued)

cup of raw or $1 / 2$ cup of cooked vegetables or $3 / 4$ cup of juice, 1 medium-sized fruit or $1 / 2$ cup of fresh, cooked, or canned fruit or $3 / 4$ cup of juice. A dietitian provided advice on purchasing produce, recipes, and easy-to-prepare dishes. Participants were also invited to attend group meetings with cooking instructions and demonstrations every month.

Nutritional Counselling: nutritional counselling based on published guidelines on how to maintain a healthy diet

The follow-up period was 6 months from the start of the intervention period.

\begin{tabular}{ll}
\hline Outcomes $\quad$ Lipid levels \\
\hline Notes
\end{tabular}

\section{Risk of bias}

\begin{tabular}{|c|c|c|}
\hline Bias & Authors' judgement & Support for judgement \\
\hline $\begin{array}{l}\text { Random sequence genera- } \\
\text { tion (selection bias) }\end{array}$ & Unclear risk & No information. Only states that trial was randomised \\
\hline $\begin{array}{l}\text { Allocation concealment } \\
\text { (selection bias) }\end{array}$ & Unclear risk & No information provided \\
\hline $\begin{array}{l}\text { Blinding of participants } \\
\text { and personnel (perfor- } \\
\text { mance bias) }\end{array}$ & High risk & $\begin{array}{l}\text { Participants: Not stated but impossible to blind participants and personnel to } \\
\text { advice }\end{array}$ \\
\hline All outcomes & & Physicians: Not stated \\
\hline $\begin{array}{l}\text { Blinding of outcome as- } \\
\text { sessment (detection bias) } \\
\text { All outcomes }\end{array}$ & Low risk & Lab technicians were blinded to outcome assessment \\
\hline $\begin{array}{l}\text { Incomplete outcome data } \\
\text { (attrition bias) } \\
\text { All outcomes }\end{array}$ & Unclear risk & No reasons for missing data provided \\
\hline $\begin{array}{l}\text { Selective reporting (re- } \\
\text { porting bias) }\end{array}$ & High risk & $\begin{array}{l}\text { Although lipid levels have been reported their analysis was not mentioned in } \\
\text { the section of the paper reporting statistical analyses }\end{array}$ \\
\hline Other bias & Unclear risk & Insufficient information to judge \\
\hline
\end{tabular}

Smith-Warner 2000

\section{Study characteristics}

\begin{tabular}{|c|c|}
\hline Methods & RCT on advice to increase fruit and vegetable consumption \\
\hline \multirow[t]{3}{*}{ Participants } & $\begin{array}{l}\text { Digestive healthcare patients aged } 30-74 \text { years recruited from a large community based gastroenterolo- } \\
\text { gy practice. Two hundred and one participants were randomised to two arms - Those asked to increase } \\
\text { fruit and vegetable intake to at least eight servings per day or to continue their usual diet. }\end{array}$ \\
\hline & Inclusion criteria: a diagnosis of colorectal adenomatous polyps in the preceding five years. \\
\hline & $\begin{array}{l}\text { Exclusion criteria: body weight }>150 \% \text { of desirable weight-for-height, medical conditions including } \\
\text { gastrointestinal disorders, diabetes mellitus, cardiovascular disease, cancer or any serious health con- } \\
\text { dition that would limit participation, those following diabetic, vegetarian and renal-disease diets, }\end{array}$ \\
\hline
\end{tabular}


Smith-Warner 2000 (Continued)

those with food sensitivities, those with plans to relocate or travel extensively, involvement in any other study requiring dietary change, pregnant women, consumption of $>35$ alcoholic beverages a week, urinary protein levels of $\geq 30 \mathrm{mg} / \mathrm{dL}$, urinary glucose levels of $\geq 0.25 \mathrm{~g} / \mathrm{dL}$ and refusal to participate or sign consent.

One hundred participants were randomised to receive advice to increase fruit and vegetable intake (age 58.6; 71\% men, 99\% white; 17\% smokers; Men BMI 28.3, Women BMI 25.8) and one hundred and one participants randomised to continue their usual diet (age 60.0; 71.3\% men, 99\% white; 17.8\% smokers; Men BMI 28.4, Women BMI 26.2). The country of publication was the U.S.A.

Interventions

Advice group: Advice to increase fruit and vegetable consumption to at least 8 servings per day before 3 -month clinic visit. After randomisation participants met with a nutritionist to formulate a plan for gradually increasing fruit and vegetables. Initial goal was to increase fruit and vegetable consumption to at least 2 servings per day. Participants were also taught behaviour modification strategies to identify personal barriers to adherence and to develop plans to overcome these. Education materials such as tip sheets and cookbooks were also provided along with quarterly newsletters, and a list of high bcarotene fruit and vegetables. Visit reminder cards, telephone follow-up for rescheduling missed visits, refrigerator magnets, newsletters, "carrot" birthday cards, and fruit and vegetable calendars were used as memory prompts and to enhance participant identification with the project. Positive reinforcement and feedback was also used by the study team and the intervention attempted to enhance spousal and family support. After the initial visit to the nutritionist, participants visited the nutritionist for individual dietary advice an additional four times.

Control group: asked to follow usual diet

The follow - up period was 1 year

Outcomes BP, lipid levels and adverse effects

Notes

\section{Risk of bias}

\begin{tabular}{|c|c|c|}
\hline Bias & Authors' judgement & Support for judgement \\
\hline $\begin{array}{l}\text { Random sequence genera- } \\
\text { tion (selection bias) }\end{array}$ & Unclear risk & Method of randomisation was not given \\
\hline $\begin{array}{l}\text { Allocation concealment } \\
\text { (selection bias) }\end{array}$ & Unclear risk & Information on the method of allocation concealment was not provided \\
\hline $\begin{array}{l}\text { Blinding of participants } \\
\text { and personnel (perfor- } \\
\text { mance bias) } \\
\text { All outcomes }\end{array}$ & High risk & $\begin{array}{l}\text { No information on blinding was provided but impossible to blind participants } \\
\text { and personnel to advice }\end{array}$ \\
\hline $\begin{array}{l}\text { Blinding of outcome as- } \\
\text { sessment (detection bias) } \\
\text { All outcomes }\end{array}$ & Unclear risk & No information on blinding was provided \\
\hline $\begin{array}{l}\text { Incomplete outcome data } \\
\text { (attrition bias) } \\
\text { All outcomes }\end{array}$ & Low risk & Intention-to-treat analysis was used \\
\hline $\begin{array}{l}\text { Selective reporting (re- } \\
\text { porting bias) }\end{array}$ & Unclear risk & Insufficient information to judge \\
\hline Other bias & Unclear risk & Insufficient information to judge \\
\hline
\end{tabular}


Thies 2012

\section{Study characteristics}

\begin{tabular}{|c|c|c|}
\hline Methods & \multicolumn{2}{|c|}{ RCT of the provision of fruit and vegetables to increase consumption } \\
\hline \multirow[t]{3}{*}{ Participants } & \multirow{2}{*}{\multicolumn{2}{|c|}{$\begin{array}{l}\text { Healthy men and women aged 40-65 years were recruited from the surrounding community of Ab- } \\
\text { erdeen. Two hundred and forty-seven participants were recruited and randomised to three arms - High } \\
\text { tomato diet, Lycopene or the control group (low tomato diet). } \\
\text { Exclusion criteria: diagnosed CVD, diabetes, fasting blood glucose of }>7.0 \mathrm{mmol} / \mathrm{L} \text {, asthma, SBP > } 160 \\
\mathrm{mmHg} \text { and DBP }>99 \mathrm{mmHg} \text {, or a thyroid condition. }\end{array}$}} \\
\hline & & \\
\hline & \multicolumn{2}{|c|}{$\begin{array}{l}\text { Eighty-four participants were randomised to receive the high tomato diet (age } 51.0 \pm 0.7 \text { ) and eighty- } \\
\text { one participants were randomised to the control ( age } 51.1 \pm 0.7 \text { ). The country of publication was the } \\
\text { UK. }\end{array}$} \\
\hline \multirow[t]{3}{*}{ Interventions } & \multicolumn{2}{|c|}{$\begin{array}{l}\text { Provision group: provided with tomato-based products (tomato sauces, juice, ketchup, soup, puree } \\
\text { and canned tomatoes) for } 12 \text { weeks. Aside from these products participants selected their own foods to } \\
\text { eat. }\end{array}$} \\
\hline & \multicolumn{2}{|c|}{$\begin{array}{l}\text { Control group: Intake of tomato-based products was restricted. Participants could not consume pas- } \\
\text { sata, canned tomatoes, cooked tomatoes, tomato paste, puree, pizza, salsa, chutney, canned beans, } \\
\text { spaghetti, ravioli in tomato sauce, barbecue sauce, brown sauce, pink grapefruit, guava, watermelon } \\
\text { and apricots. They could consume up to one portion of tomato soup, juice or sauce per week and either } \\
\leq 4 \text { raw tomatoes or } 24 \text { cherry tomatoes a week or } \leq \text { one portion of tomato ketchup a week. }\end{array}$} \\
\hline & \multicolumn{2}{|c|}{ The follow-up period was 12 weeks. } \\
\hline Outcomes & \multicolumn{2}{|l|}{ BP and lipids } \\
\hline \multicolumn{3}{|l|}{ Notes } \\
\hline \multicolumn{3}{|l|}{ Risk of bias } \\
\hline Bias & Authors' judgement & Support for judgement \\
\hline $\begin{array}{l}\text { Random sequence genera- } \\
\text { tion (selection bias) }\end{array}$ & Unclear risk & Method of randomisation was not given \\
\hline $\begin{array}{l}\text { Allocation concealment } \\
\text { (selection bias) }\end{array}$ & Unclear risk & Information on the method of allocation concealment was not provided \\
\hline $\begin{array}{l}\text { Blinding of participants } \\
\text { and personnel (perfor- } \\
\text { mance bias) } \\
\text { All outcomes }\end{array}$ & High risk & Single-blind \\
\hline
\end{tabular}

\begin{tabular}{|c|c|c|}
\hline $\begin{array}{l}\text { Blinding of outcome as- } \\
\text { sessment (detection bias) } \\
\text { All outcomes }\end{array}$ & Unclear risk & No information was provided \\
\hline $\begin{array}{l}\text { Incomplete outcome data } \\
\text { (attrition bias) } \\
\text { All outcomes }\end{array}$ & Low risk & $\begin{array}{l}\text { Number of drop-outs given by group and reasonably well balanced across } \\
\text { groups. }\end{array}$ \\
\hline $\begin{array}{l}\text { Selective reporting (re- } \\
\text { porting bias) }\end{array}$ & Low risk & Primary and secondary outcomes were clearly stated and reported \\
\hline
\end{tabular}


Thies 2012 (Continued)
Other bias
Unclear risk
Insufficient information to judge

BP: blood pressure

CVD: cardiovascular disease

DBP: diastolic blood pressure

FV: fruit and vegetables

g/d: grams per day

HDL-C: high-density lipoprotein cholesterol

$\mathrm{RCT}$ : randomised controlled trial

SBP: systolic blood pressure

SD: standard deviation

TG: triglycerides

Characteristics of excluded studies [ordered by study ID]

\begin{tabular}{|c|c|}
\hline Study & Reason for exclusion \\
\hline Ali 1995 & Not a randomised controlled trial \\
\hline Appel 2000 & No relevant outcomes reported \\
\hline Beresford 2001 & No relevant outcomes reported \\
\hline Blum 2007 & No relevant outcomes reported \\
\hline Broekmans 2000 & No relevant outcomes reported \\
\hline DASH 1995 & Short term \\
\hline Fielding 2005 & Not minimal control \\
\hline Fuemmeler 2006 & No relevant outcomes reported \\
\hline Havas 2003 & No relevant outcomes reported \\
\hline Lehtonen 2010 & $\begin{array}{l}\text { Authors were contacted several times for information on the lifestyle intervention used in the study } \\
\text { but there was no response. Due to this we have had to assume that the lifestyle intervention for the } \\
\text { control group was not minimal and therefore excluded the study. }\end{array}$ \\
\hline Lutz 1999 & No relevant outcomes reported \\
\hline Nomikos 2007 & No relevant outcomes reported \\
\hline Porrini 2011 & Ongoing trial. Period of follow-up less than 3 months \\
\hline Rock 2001 & No relevant outcomes reported \\
\hline Singh 1992 & $\begin{array}{l}\text { BMJ claims fraudulent data. } \\
\text { http://www.bmj.com/content/suppl/2005/07/28/331.7511.281.DC1 }\end{array}$ \\
\hline Sorensen 1999 & No relevant outcomes reported \\
\hline Staten 2004 & Multifactorial intervention \\
\hline
\end{tabular}




\begin{tabular}{ll}
\hline Study & Reason for exclusion \\
\hline Steptoe 2004 & Not minimal control \\
\hline Svetkey 2003 & Multifactorial intervention and includes weight loss \\
\hline Takai 2003 & Not minimal control \\
\hline Thomson 2011 & Ongoing trial. Period of follow-up less than 3 months \\
\hline Verlangieri 1985 & Not a randomised controlled trial \\
\hline WHI & Multifactorial intervention \\
\hline Winham 2007 & Not minimal control \\
\hline
\end{tabular}

Characteristics of studies awaiting classification [ordered by study ID]

\section{George 2009}

Methods Two randomised, controlled, cross-over, dietary intervention studies

Participants

In the first study there were 39 volunteers and in the second study there were 24 volunteers

Blood and urine samples were collected throughout both studies and real-time measurements of vascular tone were performed using laser Doppler imaging with iontophoresis.

Interventions
(FVP), or fruit-flavoured control, daily for six weeks. In the second study the volunteers consumed
$400 \mathrm{~mL}$ FVPJ, or sugar-matched control, on the morning of the study day.

\begin{tabular}{ll}
\hline Outcomes & Measures of vascular tone, vasodilation \\
\hline Notes & Waiting for the library to find and send full text.
\end{tabular}

\section{Groen 1952}

\begin{tabular}{ll}
\hline Methods & Unknown \\
\hline Participants & $\begin{array}{l}\text { Thirty men and } 30 \text { women were chosen from } 100 \text { volunteers on the basis of normal clinical and lab- } \\
\text { oratory findings and estimated idealism and intelligence. Twenty-two men and } 22 \text { women were } \\
\text { between } 20 \text { and } 30 \text { years of age, } 6 \text { men and } 7 \text { women were between } 30 \text { and } 40 \text { years of age, while } 2 \\
\text { men and } 1 \text { woman were between } 40 \text { and } 48 \text { years of age. }\end{array}$ \\
\hline
\end{tabular}

Interventions

Three different diets were administered to the participants in 3 successive 12-week periods, under expert supervision in a communal dining room. Diet $\mathrm{V}$ was almost exclusively vegetable, except for skimmed milk and buttermilk ad lib., and $100 \mathrm{~g}$. whole milk per day. Diet L consisted of $50 \mathrm{~g}$. of meat, $30 \mathrm{~g}$. of cheese, 0.5 litres of milk per day, 2 eggs per week, and vegetables ad lib. Diet $\mathrm{H}$ contained $250 \mathrm{~g}$. of meat, $50 \mathrm{~g}$. of cheese and 2 eggs per day besides unlimited milk, cream and butter.

\begin{tabular}{ll}
\hline Outcomes & Serum cholesterol \\
\hline Notes & $\begin{array}{l}\text { Need Information on type of study as unsure if participants were randomised to groups. Waiting for } \\
\text { the library to find and send full text. }\end{array}$
\end{tabular}


Teeple (2011)

\begin{tabular}{ll}
\hline Methods & $\begin{array}{l}\text { Randomised controlled Trial (states participants were randomly assigned to one of four treatment } \\
\text { groups) }\end{array}$ \\
\hline Participants & Postmenopausual women who smoked \\
\hline Interventions & $45 \mathrm{~g} /$ day of blackberries, $45 \mathrm{~g} /$ day of blueberries, smokers, non-smokers \\
\hline Outcomes & Lipids \\
\hline Notes & $\begin{array}{l}\text { This thesis has been ordered but is awaiting classification as lipid data are needed, as is clarifica- } \\
\text { tion of the number of participants randomised and randomisation processes. }\end{array}$
\end{tabular}

Wallace 2012

\begin{tabular}{ll}
\hline Methods & Randomised controlled trial \\
\hline Participants & $\begin{array}{l}105 \text { overweight, non-diabetic individuals with no history of cardiovascular disease - mean age } 56 \\
\text { years (range } 40-77 \text { years), } 62 \% \text { men, body mass index } 30.8 \mathrm{~kg} / \mathrm{m}^{2}\left(\mathrm{range} 26.9-37.3 \mathrm{~kg} / \mathrm{m}^{2}\right), \mathrm{fasting} \\
\text { plasma glucose } 97 \mathrm{mg} / \mathrm{dL}(\text { range } 79-121 \mathrm{mg} / \mathrm{dL}) .\end{array}$ \\
\hline Interventions & $\begin{array}{l}\text { After a 4-week wash-out diet of } 1-2 \text { portions FV per day, participants were randomised to consume } \\
1-2,4 \text { or } 7 \text { or more portions FV daily for } 12 \text { weeks. }\end{array}$ \\
\hline Outcomes & Measures of whole-body, peripheral or hepatic insulin resistance (see table), adiponectin, hsCRP, \\
\hline BP or lipid concentrations.
\end{tabular}

BMI: body mass index

BP: blood pressure

hsCRP: high-sensitivity C-reactive protein

Characteristics of ongoing studies [ordered by study ID]

\begin{tabular}{|c|c|}
\hline Study name & $\begin{array}{l}\text { The effect of one avocado per day on established and emerging cardiovascular disease (CVD) risk } \\
\text { factors }\end{array}$ \\
\hline Methods & Open label randomised cross-over trial \\
\hline \multirow[t]{5}{*}{ Participants } & Inclusion Criteria: \\
\hline & 1.healthy non-smoking \\
\hline & 2.overweight (BMI $\left.25-35 \mathrm{~kg} / \mathrm{m}^{2}\right)$ men and women \\
\hline & $\begin{array}{l}\text { 3.LDL-C between the25-90th percentile from NHANES: } 105-194 \mathrm{mg} / \mathrm{dL} \text { for males; } 98-190 \mathrm{mg} / \mathrm{dL} \text { for } \\
\text { females) }\end{array}$ \\
\hline & 4) $21-70$ years \\
\hline
\end{tabular}


Provide $\sim 24 \%$ of calories from fat and meet the Saturated Fatty Acid (SFA) and cholesterol recommendations of a Step-II diet recommended by the National Heart, Lung, and Blood Association's National Cholesterol Education Program. SFA will provide $7 \%$ of calories, and cholesterol will be less than $200 \mathrm{mg} /$ day. Vegetables and fruits in the Lower fat diet will be selected from foods that are low in antioxidants.

\section{2) Moderate fat diet}

This diet is designed to be the control diet for the avocado diet and will have an identical fatty acid profile. MUFA-enriched food (fats) will be substituted for avocado. The substitution foods will not contain antioxidant or cholesterol-lowering components similar to those in avocado.

\section{3) Avocado diet}

Designed to ensure that all participants incorporate 1 avocado ( 136g) per day into a moderate fat diet. Both the lower fat diet and avocado diet will be matched for SFA and dietary cholesterol, but will differ in total fat, primarily MUFA as provided by the avocado. The moderate fat plus avocado diet will provide $34 \%$ of calories from total fat, $18 \%$ calories from MUFA, and $9 \%$ calories from PUFA.

Outcomes
$\begin{aligned} & \text { 1) Lipoprotein profile (Week } 7 \text { ) } \\ & \text { 2) Lipoprotein profile (Week 14) } \\ & \text { 3) Lipoprotein profile (Week 21) } \\ & \text { Secondary outcomes: } \\ & \text { 1) Paraoxonase 1(PON1) activity } \\ & \text { 2) Oxidized-LDL } \\ & \text { 3) Lipid hydroperoxide } \\ & \text { 4) Macrophage cholesterol efflux }\end{aligned}$

Starting date November 2010

\section{DATA AND ANALYSES}


Comparison 1. Advice to eat fruit and vegetables

\begin{tabular}{|c|c|c|c|c|}
\hline Outcome or subgroup title & No. of studies & $\begin{array}{l}\text { No. of partici- } \\
\text { pants }\end{array}$ & Statistical method & Effect size \\
\hline $\begin{array}{l}1.1 \text { Systolic blood pressure, change } \\
\text { from baseline }(\mathrm{mmHg})\end{array}$ & 2 & 891 & $\begin{array}{l}\text { Mean Difference (IV, Fixed, } \\
95 \% \mathrm{Cl})\end{array}$ & $-3.00[-4.92,-1.09]$ \\
\hline $\begin{array}{l}\text { 1.2 Diastolic blood pressure, change } \\
\text { from baseline }(\mathrm{mmHg})\end{array}$ & 2 & 891 & $\begin{array}{l}\text { Mean Difference (IV, Fixed, } \\
95 \% \mathrm{Cl} \text { ) }\end{array}$ & $-0.90[-2.03,0.24]$ \\
\hline $\begin{array}{l}\text { 1.3 Total cholesterol, change from } \\
\text { baseline }(\mathrm{mmol} / \mathrm{l})\end{array}$ & 4 & 970 & $\begin{array}{l}\text { Mean Difference (IV, Fixed, } \\
95 \% \mathrm{Cl} \text { ) }\end{array}$ & $-0.01[-0.11,0.09]$ \\
\hline $\begin{array}{l}\text { 1.4 LDL cholesterol, change from base- } \\
\text { line ( } \mathrm{mmol} / \mathrm{l})\end{array}$ & 2 & 251 & $\begin{array}{l}\text { Mean Difference (IV, Fixed, } \\
95 \% \mathrm{Cl} \text { ) }\end{array}$ & $-0.17[-0.38,0.03]$ \\
\hline $\begin{array}{l}\text { 1.5 HDL cholesterol, change from base- } \\
\text { line }(\mathrm{mmol} / \mathrm{l})\end{array}$ & 2 & 251 & $\begin{array}{l}\text { Mean Difference (IV, Fixed, } \\
95 \% \mathrm{Cl})\end{array}$ & $-0.01[-0.10,0.08]$ \\
\hline $\begin{array}{l}\text { 1.6 Triglycerides, change from baseline } \\
(\mathrm{mmol} / \mathrm{l})\end{array}$ & 3 & 280 & $\begin{array}{l}\text { Mean Difference (IV, Fixed, } \\
95 \% \mathrm{Cl})\end{array}$ & $0.10[-0.06,0.27]$ \\
\hline
\end{tabular}

\section{Analysis 1.1. Comparison 1: Advice to eat fruit and vegetables, Outcome 1: Systolic blood pressure, change from baseline ( $\mathrm{mmHg}$ )}

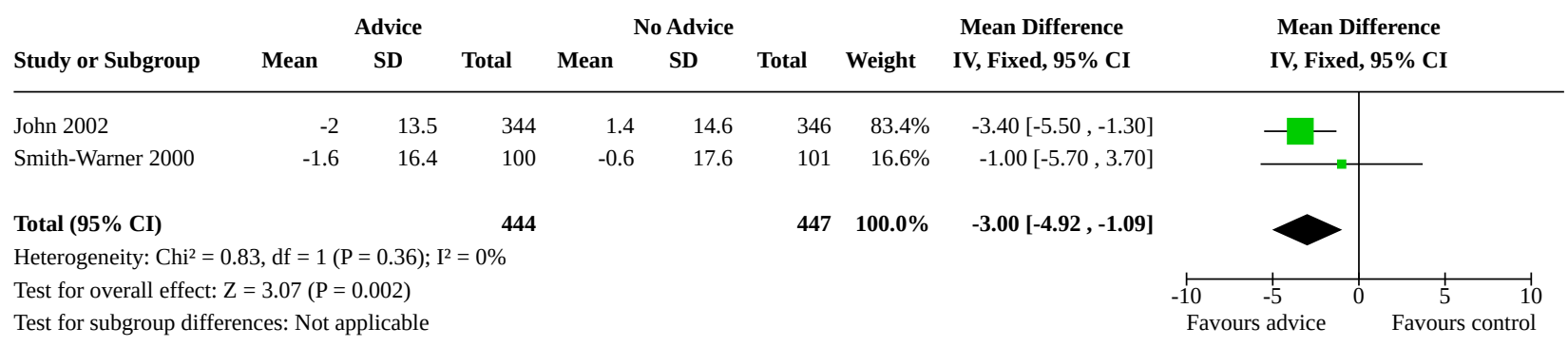

Analysis 1.2. Comparison 1: Advice to eat fruit and vegetables, Outcome 2: Diastolic blood pressure, change from baseline $(\mathrm{mmHg})$

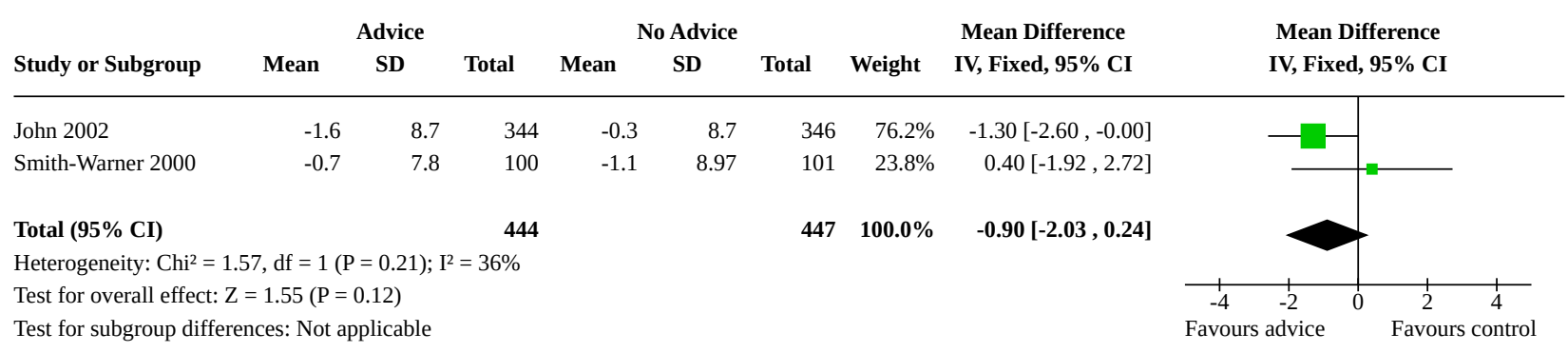


Analysis 1.3. Comparison 1: Advice to eat fruit and vegetables, Outcome 3: Total cholesterol, change from baseline $(\mathrm{mmol} / \mathrm{l})$

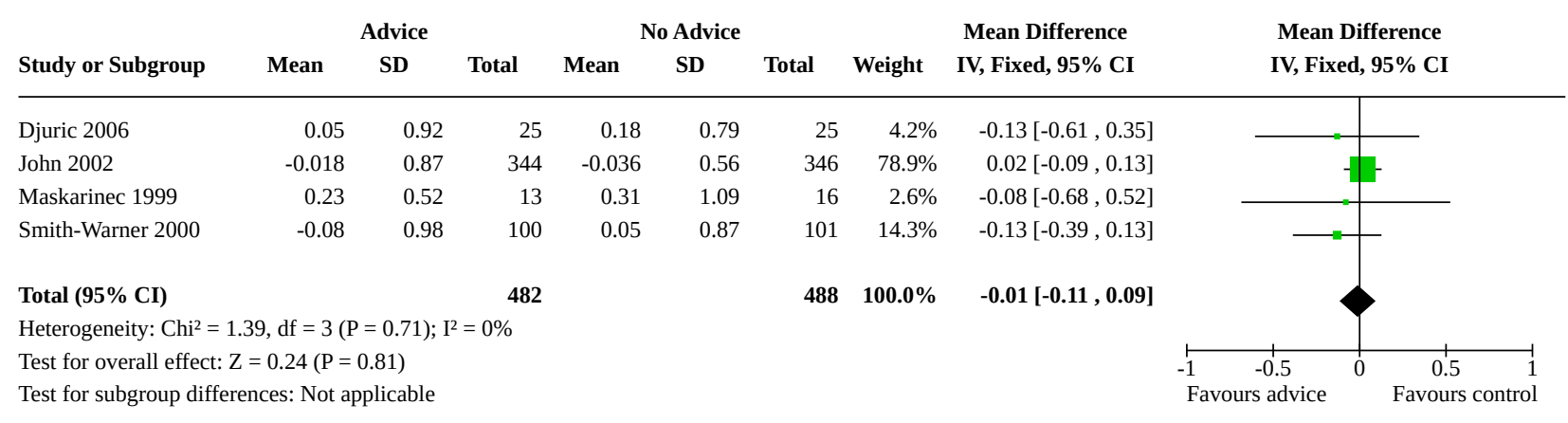

\section{Analysis 1.4. Comparison 1: Advice to eat fruit and vegetables, Outcome 4: LDL cholesterol, change from baseline ( $\mathrm{mmol} / \mathrm{l}$ )}

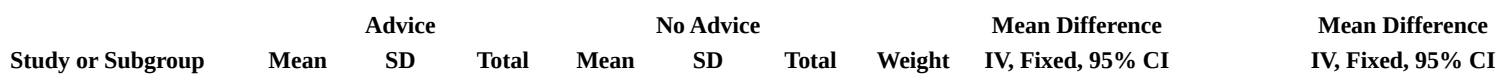

\begin{tabular}{lrrrrrrrr}
\hline Djuric 2006 & 0.06 & 0.85 & 25 & 0.28 & 0.79 & 25 & $20.7 \%$ & $-0.22[-0.67,0.23]$ \\
Smith-Warner 2000 & -0.09 & 0.89 & 100 & 0.07 & 0.79 & 101 & $79.3 \%$ & $-0.16[-0.39,0.07]$ \\
& & & & & & & & \\
Total (95\% CI) & & & $\mathbf{1 2 5}$ & & & $\mathbf{1 2 6}$ & $\mathbf{1 0 0 . 0} \%$ & $\mathbf{- 0 . 1 7}[-\mathbf{0 . 3 8 , 0 . 0 3 ]}$
\end{tabular}

Heterogeneity: $\mathrm{Chi}^{2}=0.05, \mathrm{df}=1(\mathrm{P}=0.82) ; \mathrm{I}^{2}=0 \%$

Test for overall effect: $\mathrm{Z}=1.63(\mathrm{P}=0.10)$

Test for subgroup differences: Not applicable

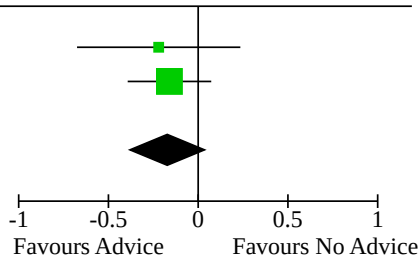

Analysis 1.5. Comparison 1: Advice to eat fruit and vegetables, Outcome 5: HDL cholesterol, change from baseline ( $\mathrm{mmol} / \mathrm{l}$ )

\begin{tabular}{|c|c|c|c|c|c|c|c|c|c|}
\hline Study or Subgroup & \multicolumn{3}{|c|}{ Advice } & \multicolumn{3}{|c|}{ No Advice } & Weight & $\begin{array}{c}\text { Mean Difference } \\
\text { IV, Fixed, 95\% CI }\end{array}$ & $\begin{array}{c}\text { Mean Difference } \\
\text { IV, Fixed, 95\% CI }\end{array}$ \\
\hline Djuric 2006 & -0.02 & 0.37 & 25 & 0 & 0.31 & 25 & $21.2 \%$ & $-0.02[-0.21,0.17]$ & - \\
\hline Smith-Warner 2000 & -0.05 & 0.35 & 100 & -0.04 & 0.36 & 101 & $78.8 \%$ & $-0.01[-0.11,0.09]$ & \\
\hline Total $(95 \%$ CI $)$ & & & 125 & & & 126 & $100.0 \%$ & $-0.01[-0.10,0.08]$ & \\
\hline \multicolumn{10}{|c|}{ Heterogeneity: $\mathrm{Chi}^{2}=0.01, \mathrm{df}=1(\mathrm{P}=0.93) ; \mathrm{I}^{2}=0 \%$} \\
\hline \multicolumn{9}{|c|}{ Test for overall effect: $\mathrm{Z}=0.27(\mathrm{P}=0.79)$} & -0.5 \\
\hline Test for subgroup diff & ces: Not al & plicable & & & & & & & Favours Advice \\
\hline
\end{tabular}

\section{Analysis 1.6. Comparison 1: Advice to eat fruit and vegetables, Outcome 6: Triglycerides, change from baseline ( $\mathrm{mmol} / \mathrm{l})$}

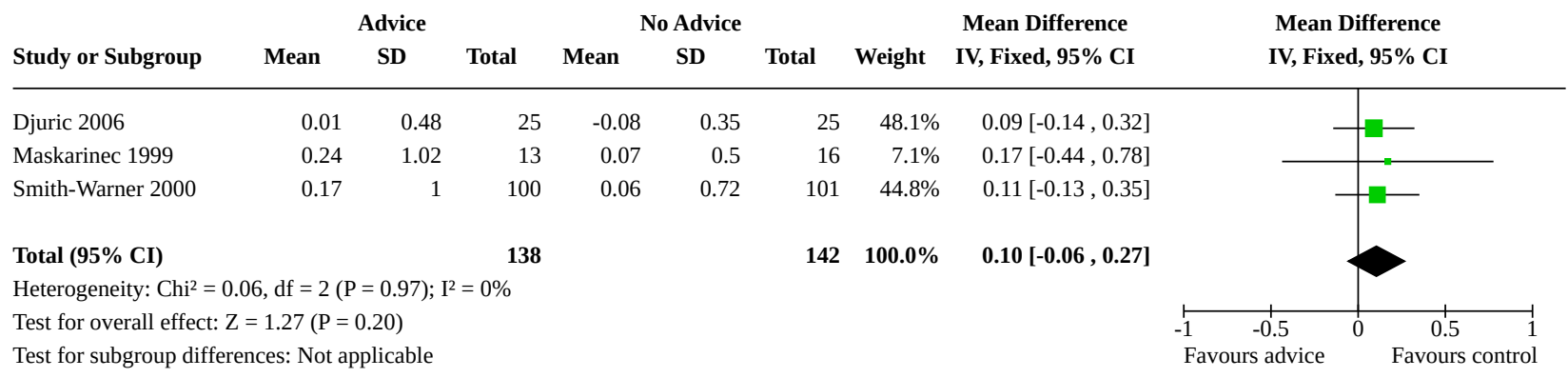


Comparison 2. Provision of fruit and vegetables

\begin{tabular}{|c|c|c|c|c|}
\hline Outcome or subgroup title & No. of studies & $\begin{array}{l}\text { No. of partici- } \\
\text { pants }\end{array}$ & Statistical method & Effect size \\
\hline $\begin{array}{l}2.1 \text { Systolic blood pressure, change from } \\
\text { baseline }(\mathrm{mmHg})\end{array}$ & 1 & 157 & $\begin{array}{l}\text { Mean Difference (IV, Fixed, } \\
95 \% \mathrm{CI})\end{array}$ & $1.00[0.45,1.55]$ \\
\hline $\begin{array}{l}\text { 2.2 Diastolic blood pressure, change } \\
\text { from baseline }(\mathrm{mmHg})\end{array}$ & 1 & 157 & $\begin{array}{l}\text { Mean Difference (IV, Fixed, } \\
95 \% \mathrm{CI})\end{array}$ & $1.50[1.18,1.82]$ \\
\hline $\begin{array}{l}\text { 2.3 Total cholesterol, change from base- } \\
\text { line }(\mathrm{mmol} / \mathrm{l})\end{array}$ & 2 & 187 & $\begin{array}{l}\text { Mean Difference (IV, Ran- } \\
\text { dom, } 95 \% \mathrm{CI} \text { ) }\end{array}$ & $-0.10[-0.24,0.04]$ \\
\hline $\begin{array}{l}\text { 2.4 LDL cholesterol, change from base- } \\
\text { line ( } \mathrm{mmol} / \mathrm{l})\end{array}$ & 3 & & $\begin{array}{l}\text { Mean Difference (IV, Fixed, } \\
95 \% \mathrm{CI})\end{array}$ & $\begin{array}{l}\text { Totals not select- } \\
\text { ed }\end{array}$ \\
\hline $\begin{array}{l}2.5 \mathrm{HDL} \text { cholesterol, change from base- } \\
\text { line }(\mathrm{mmol} / \mathrm{l})\end{array}$ & 3 & & $\begin{array}{l}\text { Mean Difference (IV, Fixed, } \\
95 \% \mathrm{Cl})\end{array}$ & $\begin{array}{l}\text { Totals not select- } \\
\text { ed }\end{array}$ \\
\hline $\begin{array}{l}\text { 2.6 Trigylcerides, change from baseline } \\
(\mathrm{mmol} / \mathrm{l})\end{array}$ & 3 & 284 & $\begin{array}{l}\text { Mean Difference (IV, Fixed, } \\
95 \% \mathrm{Cl})\end{array}$ & $-0.01[-0.03,0.01]$ \\
\hline
\end{tabular}

Analysis 2.1. Comparison 2: Provision of fruit and vegetables, Outcome 1: Systolic blood pressure, change from baseline ( $\mathrm{mmHg}$ )

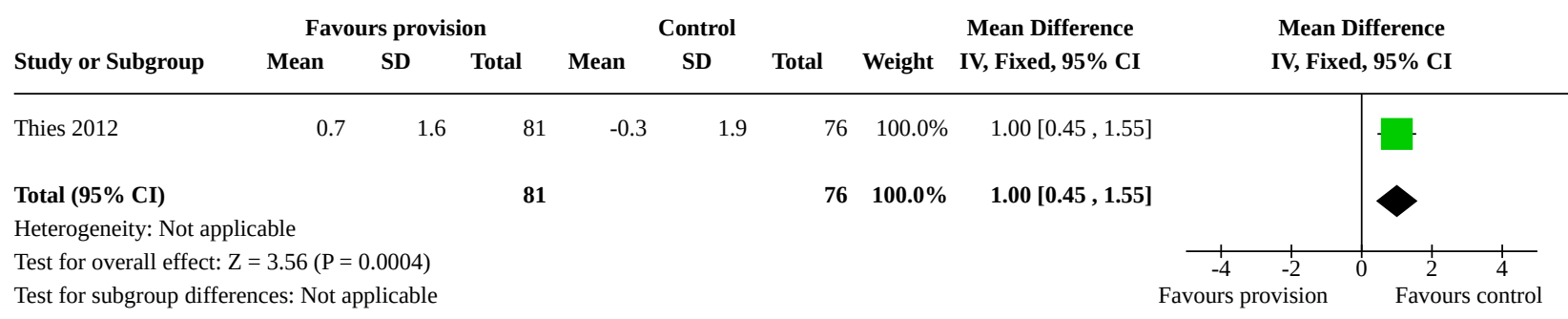

Analysis 2.2. Comparison 2: Provision of fruit and vegetables, Outcome 2: Diastolic blood pressure, change from baseline ( $\mathrm{mmHg}$ )

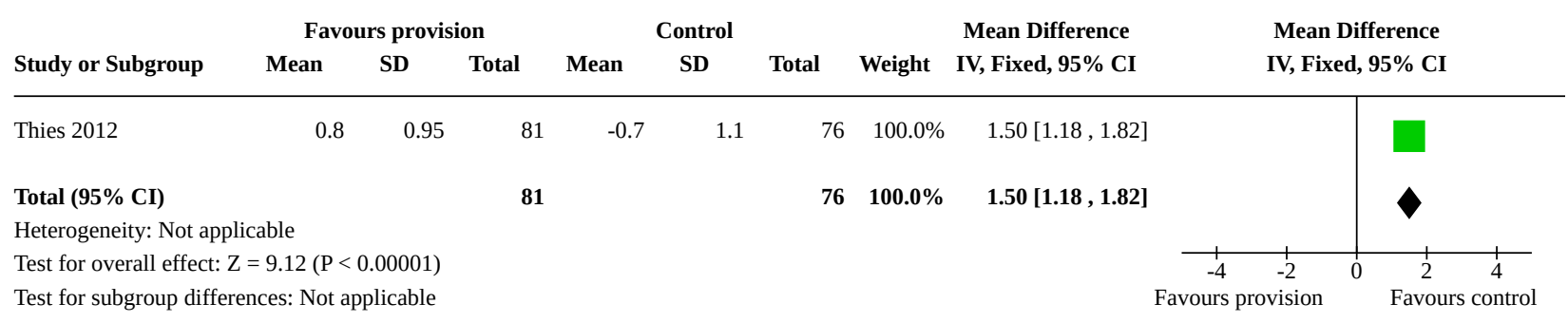


Analysis 2.3. Comparison 2: Provision of fruit and vegetables, Outcome 3: Total cholesterol, change from baseline ( $\mathrm{mmol} / \mathrm{l}$ )

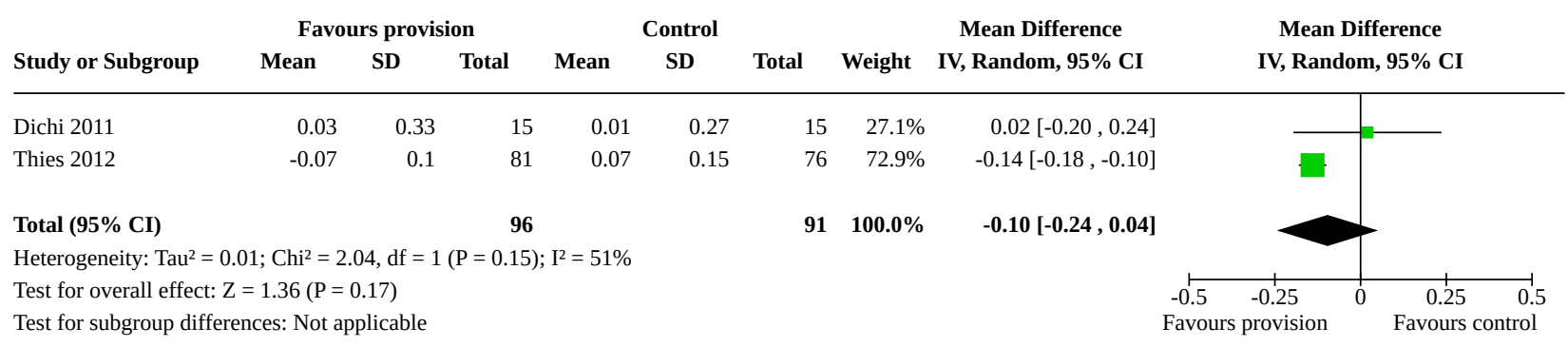

Analysis 2.4. Comparison 2: Provision of fruit and vegetables, Outcome 4: LDL cholesterol, change from baseline ( $\mathrm{mmol} / \mathrm{l}$ )

\begin{tabular}{lcccccccc} 
& \multicolumn{2}{c}{ Favours provision } & \multicolumn{2}{c}{ Favours Control } & \multicolumn{2}{c}{ Mean Difference } & Mean Difference \\
Study or Subgroup & Mean & SD & Total & Mean & SD & Total & IV, Fixed, 95\% CI & IV, Fixed, 95\% CI
\end{tabular}

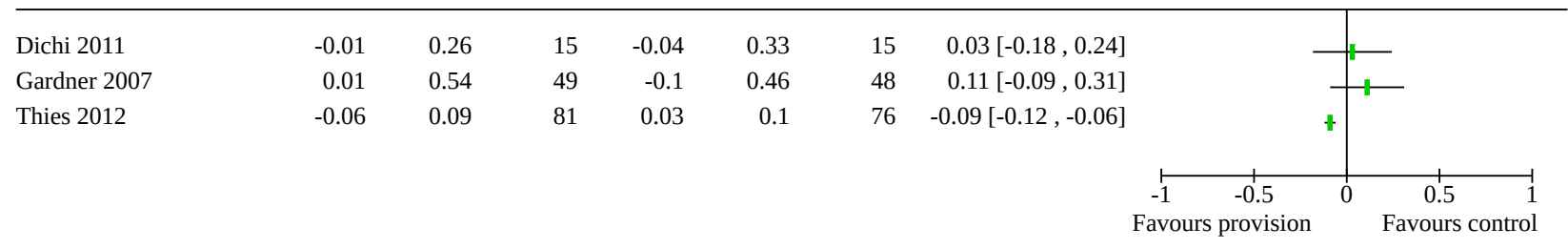

\section{Analysis 2.5. Comparison 2: Provision of fruit and vegetables, Outcome 5: HDL cholesterol, change from baseline ( $\mathrm{mmol} / \mathrm{l})$}

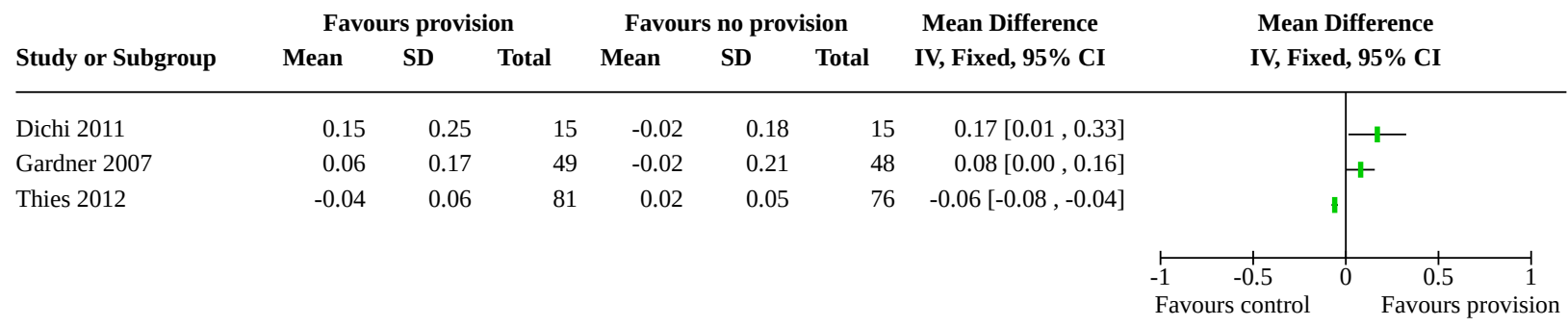

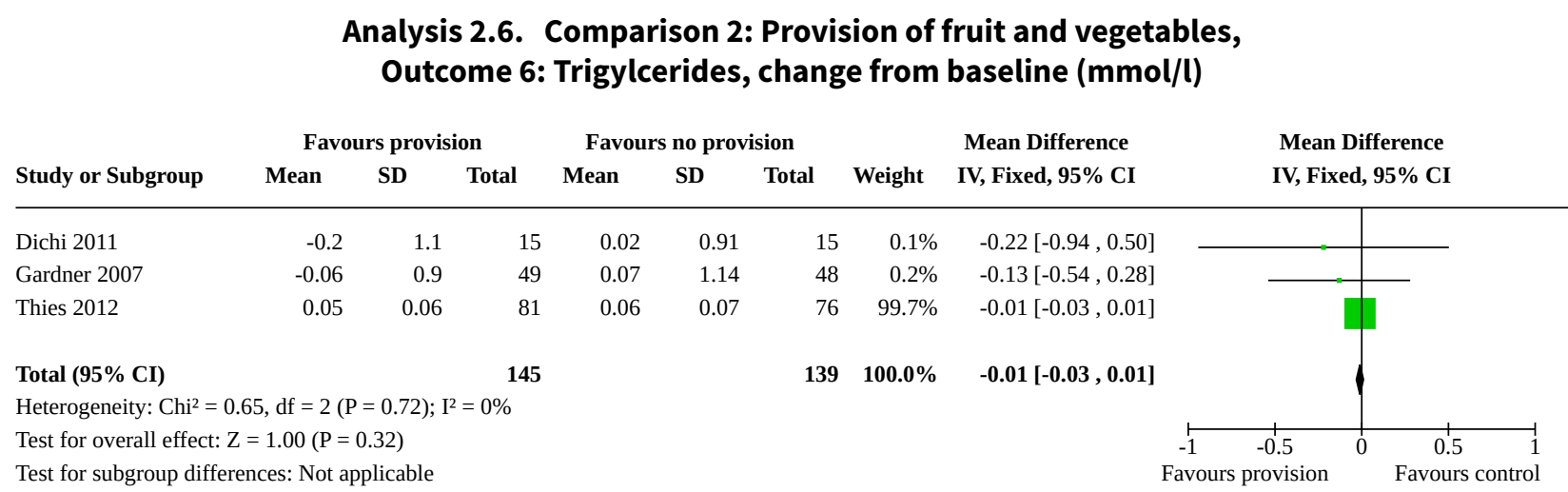




\section{APPENDICES}

\section{Appendix 1. Search strategies \\ CENTRAL}

\#1 MeSH descriptor: [Fruit] explode all trees

\#2 MeSH descriptor: [Citrus] explode all trees

\#3 MeSH descriptor: [Vegetables] explode all trees

\#4 fruit*

\#5 vegetable*

\#6 orange*

\#7 apple*

\#8 pear or pears

\#9 grape or grapes

\#10 banana*

\#11 berry or berries

\#12 citrus

\#13 carrot $^{*}$

$\# 14$ greens

\#15 cabbage*

\#16 brassica*

\#17 blackberr ${ }^{\star}$

\#18 blueberr*

\#19 cranberr*

\#20 guava*

\#21 kiwi ${ }^{\star}$

\#22 lingonberr*

\#23 mango*

\#24 melon*

\#25 papaya*

\#26 pineapple*

\#27 raspberr*

\#28 strawberr*

\#29 tomato*

\#30 potato*

\#31 onion*

\#32 grapefruit*

\#33 mandarin*

\#34 satsuma*

\#35 tangerine*

\#36 plum or plums

\#37 apricot ${ }^{\star}$

\#38 cherry or cherries

\#39 nectarine*

\#40 peach or peaches

\#41 celery

\#42 spinach*

\#43 salad or salads

\#44 pea or peas

\#45 bean or beans

\#46 broccoli

\#47 cauliflower*

\#48 beetroot ${ }^{\star}$

\#49 turnip*

\#50 rhubarb

\#51 legume*

\#52 cucumber*

\#53 leek*

\#54 aubergine*

\#55 pepper $^{\star}$

\#56 okra 
\#57 pumpkin*

\#58 squash*

\#59 artichoke*

\#60 lettuce*

\#61 kale

\#62 chard

\#63 parsnip*

\#64 asparagus

\#65 fennel

\#66 chickpea*

\#67 five-a-day

\#68 5-a-day

\#69 5 next a next day

$\# 70 \# 1$ or \#2 or \#3 or \#4 or \#5 or \#6 or \#7 or \#8 or \#9 or \#10

$\# 71 \# 11$ or \#12 or \#13 or \#14 or \#15 or \#16 or \#17 or \#18 or \#19 or \#20

$\# 72 \# 21$ or \#22 or \#23 or \#24 or \#25 or \#26 or \#27 or \#28 or \#29 or \#30

$\# 73 \# 31$ or \#32 or \#33 or \#34 or \#35 or \#36 or \#37 or \#38 or \#39 or \#40

$\# 74 \# 41$ or \#42 or \#43 or \#44 or \#45 or \#46 or \#47 or \#48 or \#49 or \#50

$\# 75 \# 51$ or \#52 or \#53 or \#54 or \#55 or \#56 or \#57 or \#58 or \#59 or \#60

$\# 76 \# 61$ or \#62 or \#63 or \#64 or \#65 or \#66 or \#67 or \#68 or \#69

$\# 77 \# 70$ or \#71 or \#72 or \#73 or \#74 or \#75 or \#76

\#78 MeSH descriptor: [Cardiovascular Diseases] explode all trees

$\# 79$ cardio*

\#80 cardia*

\#81 heart*

\#82 coronary*

$\# 83$ angina*

$\# 84$ ventric $^{*}$

\#85 myocard*

\#86 pericard $^{*}$

\#87 isch?em*

\#88 emboli*

\#89 arrhythmi*

\#90 thrombo*

\#91 atrial next fibrillat*

\#92 tachycardi*

\#93 endocardi*

\#94 sick near sinus

\#95 MeSH descriptor: [Stroke] explode all trees

\#96 stroke or stokes

\#97 cerebrovasc ${ }^{\star}$

\#98 cerebral next vascular

\#99 apoplexy

\#100 brain near/2 accident*

\#101 brain* near/2 infarct*

\#102 cerebral near/2 infarct*

\#103 lacunar near/2 infarct*

\#104 MeSH descriptor: [Hypertension] explode all trees

\#105 hypertensi*

\#106 peripheral next arter ${ }^{\star}$ next disease*

\#107 high near/2 (blood next pressure)

$\# 108$ increased near/2 (blood next pressure)

\#109 elevated near/2 (blood next pressure)

\#110 MeSH descriptor: [Hyperlipidemias] explode all trees

\#111 hyperlipid*

\#112 hyperlip?emia*

\#113 hypercholesterol ${ }^{*}$

\#114 hypercholester?emia*

\#115 hyperlipoprotein?emia*

\#116 hypertriglycerid?emia*

\#117 MeSH descriptor: [Arteriosclerosis] explode all trees

\#118 MeSH descriptor: [Cholesterol] explode all trees

Increased consumption of fruit and vegetables for the primary prevention of cardiovascular diseases (Review)

Copyright $\odot 2013$ The Cochrane Collaboration. Published by John Wiley \& Sons, Ltd. 
\#119 cholesterol

\#120 "coronary risk factor*"

\#121 MeSH descriptor: [Blood Pressure] this term only

$\# 122$ blood pressure

$\# 123 \# 78$ or \#79 or \#80 or \#81 or \#82 or \#83 or \#84 or \#85 or \#86 or \#87

$\# 124 \# 88$ or $\# 89$ or $\# 90$ or \#91 or \#92 or \#93 or \#94 or \#95 or \#96 or \#97

$\# 125 \# 98$ or \#99 or \#100 or \#101 or \#102 or \#103 or \#104 or \#105 or \#106 or \#107

$\# 126 \# 108$ or \#109 or \#110 or \#111 or \#112 or \#113 or \#114 or \#115 or \#116

$\# 127 \# 117$ or \#118 or \#119 or \#120 or \#121 or \#122

\#128 \#123 or \#124 or \#125 or \#126 or \#127

$\# 129 \# 77$ and \#128

\section{MEDLINE OVID}

1. exp Fruit/

2. exp Citrus/

3. exp Vegetables/

4. fruit*.tw.

5. vegetable ${ }^{\star}$. tw.

6. orange* .tw.

7. apple ${ }^{\star} . t w$.

8. (pear or pears).tw.

9. (grape or grapes).tw.

10. banana*.tw.

11. (berry or berries).tw.

12. citrus.tw.

13. carrot $^{\star}$. tw.

14. greens.tw.

15. cabbage*.tw.

16. brassica*.tw.

17. blackberr*.tw.

18. blueberr ${ }^{\star}$.tw.

19. cranberr $^{\star}$.tw.

20. guava*.tw.

21. kiwi ${ }^{\star}$.tw.

22. lingonberr ${ }^{\star}$. tw.

23. mango*.tw.

24. melon*.tw.

25. papaya*.tw.

26. pineapple*.tw.

27. raspberr ${ }^{\star}$. tw.

28. strawberr ${ }^{\star} . t w$.

29. tomato*.tw.

30. potato*.tw.

31. onion ${ }^{\star}$.tw.

32. grapefruit*.tw.

33. mandarin ${ }^{\star}$. tw.

34. satsuma*.tw.

35. tangerine ${ }^{\star}$.tw.

36. (plum or plums).tw.

37. apricot*.tw.

38. (cherry or cherries).tw.

39. nectarine*.tw.

40. (peach or peaches).tw.

41. celery.tw.

42. spinach $^{\star}$.tw.

43. (salad or salads).tw.

44. (pea or peas).tw.

45. (bean or beans).tw.

46. broccoli.tw.

47. cauliflower ${ }^{\star}$.tw.

48. beetroot ${ }^{\star}$.tw. 
49. turnip ${ }^{\star}$. tw.

50. rhubarb.tw.

51. legume ${ }^{\star}$. tw.

52. cucumber ${ }^{\star}$.tw.

53. leek ${ }^{\star}$.tw.

54. aubergine ${ }^{\star}$.tw.

55. pepper ${ }^{\star} . t w$.

56. okra.tw.

57. pumpkin ${ }^{\star} . t w$.

58. squash ${ }^{\star}$. tw.

59. artichoke*.tw.

60. lettuce ${ }^{\star}$. tw.

61. kale.tw.

62. chard.tw.

63. parsnip ${ }^{\star}$. tw.

64. asparagus.tw.

65. fennel.tw.

66. chickpea*.tw.

67. five-a-day.tw.

68. 5-a-day.tw.

69. or/1-68

70. exp Cardiovascular Diseases/

71. cardio*.tw.

72. cardia* .tw.

73. heart*.tw.

74. coronary ${ }^{\star} . \mathrm{tw}$.

75. angina ${ }^{\star}$.tw.

76. ventric ${ }^{\star}$. tw.

77. myocard ${ }^{*}$. tw.

78. pericard*.tw.

79. isch?em*.tw.

80. emboli*.tw.

81. arrhythmi ${ }^{\star}$.tw.

82. thrombo*.tw.

83. atrial fibrillat ${ }^{\star}$. tw.

84. tachycardi ${ }^{\star}$.tw.

85. endocardi ${ }^{\star}$. tw.

86. (sick adj sinus).tw.

87. exp Stroke/

88. (stroke or stokes).tw.

89. cerebrovasc ${ }^{\star}$.tw.

90. cerebral vascular.tw.

91. apoplexy.tw.

92. (brain adj2 accident $\left.^{\star}\right)$.tw.

93. ((brain* or cerebral or lacunar) adj2 infarct $\left.{ }^{\star}\right)$.tw.

94. exp Hypertension/

95. hypertensi ${ }^{\star}$.tw.

96. peripheral arter ${ }^{\star}$ disease ${ }^{\star} . t w$.

97. ((high or increased or elevated) adj2 blood pressure).tw.

98. exp Hyperlipidemias/

99. hyperlipid*.tw.

100. hyperlip?emia*.tw.

101. hypercholesterol*.tw.

102. hypercholester?emia ${ }^{\star} . t w$.

103. hyperlipoprotein?emia ${ }^{\star} . t w$.

104. hypertriglycerid?emia*.tw.

105. exp Arteriosclerosis/

106. exp Cholesterol/

107. cholesterol.tw.

108. "coronary risk factor* ".tw.

109. Blood Pressure/

110. blood pressure.tw.

Increased consumption of fruit and vegetables for the primary prevention of cardiovascular diseases (Review) 
111. or $/ 70-110$

112. randomized controlled trial.pt.

113. controlled clinical trial.pt.

114. randomized.ab.

115. placebo.ab.

116. drug therapy.fs.

117. randomly.ab.

118. trial.ab.

119. groups.ab.

120.112 or 113 or 114 or 115 or 116 or 117 or 118 or 119

121. exp animals/ not humans.sh.

122. 120 not 121

123. 69 and 111 and 122

EMBASE OVID

1. exp fruit/

2. exp vegetable/

3. fruit*.tw.

4. vegetable*.tw.

5. orange ${ }^{\star} . \mathrm{tw}$

6. apple ${ }^{\star} . t w$.

7. (pear or pears).tw.

8. (grape or grapes).tw.

9. banana*.tw.

10. (berry or berries).tw.

11. citrus.tw.

12. carrot $^{\star}$. tw.

13. greens.tw.

14. cabbage*.tw.

15. brassica*.tw.

16. blackberr*.tw.

17. blueberr* ${ }^{\star}$.tw.

18. cranberr $^{\star}$.tw.

19. guava*.tw.

20. kiwi ${ }^{\star}$.tw.

21. lingonberr ${ }^{\star}$. tw.

22. mango ${ }^{\star} . t w$.

23. melon ${ }^{\star}$.tw.

24. papaya*.tw.

25. pineapple ${ }^{\star}$.tw.

26. raspberr ${ }^{\star}$.tw.

27. strawberr*.tw.

28. tomato*.tw.

29. potato*.tw.

30. onion*.tw.

31. grapefruit ${ }^{\star}$.tw.

32. mandarin ${ }^{\star} . t w$.

33. satsuma*.tw.

34. tangerine ${ }^{\star}$.tw.

35. (plum or plums).tw.

36. apricot ${ }^{\star}$.tw.

37. (cherry or cherries).tw.

38. nectarine ${ }^{\star}$.tw.

39. (peach or peaches).tw.

40. celery.tw.

41. spinach*.tw.

42. (salad or salads).tw.

43. (pea or peas).tw.

44. (bean or beans).tw.

45. broccoli.tw.

46. cauliflower ${ }^{\star}$.tw. 
47. beetroot*.tw.

48. turnip ${ }^{\star}$. tw.

49. rhubarb.tw.

50. legume $e^{\star} . t w$.

51. cucumber ${ }^{\star}$.tw.

52. leek*.tw.

53. aubergine ${ }^{\star}$.tw.

54. pepper ${ }^{\star}$. tw.

55. okra.tw.

56. pumpkin*.tw.

57. squash ${ }^{\star} . t w$.

58. artichoke*.tw.

59. lettuce ${ }^{\star} . t w$.

60. kale.tw.

61. chard.tw.

62. parsnip*.tw.

63. asparagus.tw.

64. fennel.tw.

65. chickpea*.tw.

66. five-a-day.tw.

67. 5-a-day.tw.

68. or/1-67

69. exp cardiovascular disease/

70. cardio*.tw.

71. cardia*.tw.

72. heart*.tw.

73. coronary ${ }^{\star}$.tw.

74. angina*.tw.

75. ventric ${ }^{\star}$. tw.

76. myocard*.tw.

77. pericard $^{\star}$. tw.

78. isch?em ${ }^{\star}$. tw.

79. emboli*.tw.

80. arrhythmi*.tw.

81. thrombo*.tw.

82. atrial fibrillat ${ }^{\star}$.tw.

83. tachycardi ${ }^{\star}$.tw.

84. endocardi ${ }^{\star}$.tw.

85. (sick adj sinus).tw.

86. exp cerebrovascular disease/

87. (stroke or stokes).tw.

88. cerebrovasc ${ }^{\star}$.tw.

89. cerebral vascular.tw.

90. apoplexy.tw.

91. (brain adj2 accident $\left.{ }^{\star}\right)$.tw.

92. ((brain* or cerebral or lacunar) adj2 infarct $\left.{ }^{\star}\right)$.tw.

93. exp hypertension/

94. hypertensi ${ }^{\star}$.tw.

95. peripheral arter $^{\star}$ disease $^{\star}$. tw.

96. ((high or increased or elevated) adj2 blood pressure).tw.

97. exp hyperlipidemia/

98. hyperlipid ${ }^{*}$.tw.

99. hyperlip?emia*.tw.

100. hypercholesterol ${ }^{\star}$.tw.

101. hypercholester?emia*.tw.

102. hyperlipoprotein?emia*.tw.

103. hypertriglycerid?emia ${ }^{\star}$.tw.

104. exp Arteriosclerosis/

105. exp Cholesterol/

106. cholesterol.tw.

107. "coronary risk factor* ".tw.

108. Blood Pressure/ 
109. blood pressure.tw.

110. or/69-109

111. random\$.tw.

112. factorial\$.tw.

113. crossover\$.tw.

114. cross over\$.tw.

115. cross-over\$.tw.

116. placebo\$.tw.

117. (doubl\$ adj blind\$).tw.

118. (singl\$ adj blind\$).tw.

119. assign\$.tw.

120. allocat\$.tw.

121. volunteer\$.tw.

122. crossover procedure/

123. double blind procedure/

124. randomized controlled trial/

125. single blind procedure/

126. 111 or 112 or 113 or 114 or 115 or 116 or 117 or 118 or 119 or 120 or 121 or 122 or 123 or 124 or 125

127. (animal/ or nonhuman/) not human/

128. 126 not 127

129.68 and 110 and 128

\section{Web of Science}

\#22 \#21 AND \#20

\#21 TS=(random* or blind ${ }^{\star}$ or allocat ${ }^{\star}$ or assign* or trial* or placebo* or crossover ${ }^{\star}$ or cross-over $\left.^{\star}\right)$

\#20 \#19 AND \#7

\#19 \#18 OR \#17 OR \#16 OR \#15 OR \#14 OR \#13 OR \#12 OR \#11 OR \#10 OR \#9 OR \#8

\#18 TS=blood pressure

\#17 TS="coronary risk factor*"

\#16 TS=cholesterol

\#15 TS=arteriosclerosis

\#14 TS=(hyperlipid* OR hyperlip?emia* OR hypercholesterol* OR hypercholester?emia* OR hyperlipoprotein?emia* OR hypertriglycerid? emia*)

\#13 TS=("high blood pressure")

\#12 TS=(hypertensi* OR "peripheral arter* disease*")

\#11 TS=(stroke OR stokes OR cerebrovasc ${ }^{\star}$ OR cerebral OR apoplexy OR (brain SAME accident ${ }^{\star}$ ) OR (brain SAME infarct $\left.{ }^{\star}\right)$ )

\#10 TS=("atrial fibrillat*" OR tachycardi* OR endocardi*)

\#9 TS=(pericard* OR isch?em OR emboli* OR arrhythmi* OR thrombo*)

$\# 8 \mathrm{TS}=\left(\right.$ cardio* OR cardia* OR heart $^{\star}$ OR coronary ${ }^{\star}$ OR angina* OR ventric* OR myocard ${ }^{\star}$ )

\#7 \#6 OR \#5 OR \#4 OR \#3 OR \#2 OR \#1

\#6 TS=(kale or chard or parsnip* or asparagus or fennel or chickpea* or five-a-day or "five a day" or 5-a-day or "5 a day")

\#5 TS=(beetroot ${ }^{\star}$ or turnip ${ }^{\star}$ or rhubarb or legume* or cucumber ${ }^{\star}$ or leek ${ }^{\star}$ or aubergine ${ }^{\star}$ or pepper ${ }^{\star}$ or okra or pumpkin ${ }^{\star}$ or squash or $^{\star}$ artichoke* or lettuce $\left.{ }^{\star}\right)$

\#4 TS=(cherry or cherries or nectarine* or peach or peaches or celery or spinach* or salad or salads or pea or peas or bean or beans or broccoli or cauliflower $\left.{ }^{\star}\right)$

\#3 TS=(pineapple* or raspberr ${ }^{\star}$ or strawberr ${ }^{\star}$ or tomato* or potato* or onion* or grapefruit* or mandarin* or satsuma* or tangerine* or plum or plums or apricot $\left.{ }^{\star}\right)$

\#2 TS=(carrot* or greens or cabbage* or brassica* or blackberr ${ }^{\star}$ or blueberr ${ }^{\star}$ or cranberr ${ }^{\star}$ or guava* or kiwi ${ }^{\star}$ or lingonberr $^{\star}$ or mango* or melon $^{\star}$ or pap aya*)

\#1 TS=(fruit ${ }^{\star}$ or vegetable or $^{*}$ orange $e^{\star}$ or apple ${ }^{\star}$ or pear or pears or grape or grapes or banana* or berry or berries or citrus)

WHAT'S NEW

\begin{tabular}{lll}
\hline Date & Event & Description \\
\hline 17 June 2021 & Amended & Editorial note added \\
\hline
\end{tabular}




\section{HIST O R Y}

Protocol first published: Issue 5, 2012

Review first published: Issue 6, 2013

\section{CONTRIBUTIONS OF AUTHORS}

All review authors contributed to the protocol development. The Trials Search Co-ordinators of the CHG ran the searches, LH and El screened titles and abstracts and assessed studies for formal inclusion or exclusion. $\mathrm{LH}$ and $\mathrm{JH}$ abstracted data and assessed methodological quality. LH and KR conducted the analysis, and wrote the first draft of the review. All authors contributed to later drafts.

\section{DECLARATIONS OF INTEREST}

None known.

\section{SOURCES OF SUPPORT}

\section{Internal sources}

- Warwick Medical School, University of Warwick, UK

- Norwich Medical School, University of East Anglia, UK

\section{External sources}

- NIHR Cochrane Programme Grant, UK

\section{DIFFERENCES BETWEEN PROTOCOLAND REVIEW}

It was our intention to perform stratified analyses to examine the effects of intensity and duration of interventions, and different components of the intervention, but there were insufficient trials included in the review to do this. Similarly, we intended to perform sensitivity analyses to examine the effects of low methodological quality and perform funnel plots to assess publication bias. We also intended to focus on studies with follow-up of six months or more but again studies with this length of follow-up were lacking and so studies with follow-up of three months or more were included. These will be addressed in future updates of this review when more evidence accrues.

\section{N D EX TERMS}

\section{Medical Subject Headings (MeSH)}

Cardiovascular Diseases [* prevention \& control]; Consumer Health Information; *Fruit [adverse effects]; Halitosis [etiology]; Odorants; Primary Prevention [*methods]; Randomized Controlled Trials as Topic; ${ }^{\star}$ Vegetables [adverse effects]

\section{MeSH check words}

Adult; Humans 